\title{
Synaptotagmin-7 endows a population of chromaffin cell vesicles with enhanced calcium sensing and delayed content release properties
}

\author{
Bendahmane $\mathbf{M}^{1}$, Kreutzberger $A \mathrm{JB}^{2}$, Chapman-Morales $A^{1}$, Philippe $\mathrm{J}^{1}$, Schenk $\mathbf{N}^{1}$, Zhang $\mathbf{S}^{1}$, Kiessling $V^{2}$, Tamm $L^{2}$, \\ Giovannucci $\mathrm{DR}^{3}$, Jenkins $\mathrm{PM}^{1,4}$, and Anantharam $A^{1 \times}$ \\ ${ }^{1}$ Department of Pharmacology, University of Michigan Medical School, Ann Arbor, MI, 48109. \\ ${ }^{2}$ Center for Membrane and Cell Physiology and Department of Molecular Physiology and Biological Physics, University of Virginia, Charlottesville, VA 22908. \\ ${ }^{3}$ Department of Neuroscience, University of Toledo Medical School, Toledo, $\mathrm{OH} 43606$. \\ ${ }^{4}$ Department of Psychiatry, University of Michigan Medical School, Ann Arbor, MI, 48109
}

\begin{abstract}
Synaptotagmin-7 (Syt-7) is one of two major calcium sensors for exocytosis in adrenal chromaffin cells, the other being synaptotagmin-1 (Syt-1). Despite its undoubted importance, questions remain as to the functional and physiological role of Syt-7 in secretion. We examined this issue using two distinct preparations - mouse chromaffin cells lacking endogenous Syt7 (KO cells) and a reconstituted system employing cell-derived vesicles expressing either Syt-7 or Syt-1. First, we report using immunofluorescence that Syt-7 exhibits a punctate intracellular distribution consistent with its sorting to organelles, including dense core vesicles. We also find that the likelihood of vesicle fusion in KO cells is markedly lower than in WT cells. When fusion does occur, cargoes are discharged more rapidly when only Syt-1 is available to facilitate release. A distinctive characteristic of KO cells is that secretion runs down after prolonged cholinergic stimulation. In contrast, exocytosis persists in WT cells even with extended exposure to acetylcholine, suggesting a key role for Syt-7 in sustaining the secretory response. To determine the extent to which the aforementioned results are attributable purely to Syt-7, vesicles expressing only Syt-7 or Syt-1 were triggered to fuse on planar supported bilayers bearing plasma membrane SNARE proteins. Here, as in cells, Syt7 confers substantially greater calcium sensitivity to vesicle fusion than Syt-1 and slows the rate at which cargos are released. Overall, this study demonstrates that by virtue of its high affinity for calcium, Syt-7 plays a central role in regulating secretory output from adrenal chromaffin cells.
\end{abstract}

synaptotagmin | chromaffin cell | exocytosis | granule

Correspondence: arunanan@umich.edu

\section{Introduction}

Synaptotagmin-7 (Syt-7) belongs to a family of proteins, numbering 17 in total, many of which serve as $\mathrm{Ca}^{2+}$ sensors for release in a variety of secretory systems $(1,2)$. In the context of the adrenal medulla - a critical effector arm of the sympathetic nervous system - synaptotagmins regulate the release of adrenergic hormones and peptides from chromaffin cells (2). These released agents modulate the function of a multitude of peripheral organs, including the heart, lungs, and digestive system (3-6).

By now, it is generally acknowledged that Syt-7 and a related isoform, Syt-1, are responsible for the vast majority of $\mathrm{Ca}^{2+}$-dependent exocytosis from chromaffin cells (7). How- ever, there are important unresolved issues with respect to how Syt-7 operates. For example, it remains unclear as to whether Syt-7 is sorted to the plasma membrane (8) or the vesicle membrane $(9,10)$, and whether Syt-7 promotes (11), or alternatively, constrains (12) fusion pore expansion. It is also not obvious why two synaptotagmin isoforms are necessary to support exocytosis in chromaffin cells.

Here, we employ two distinct preparations to address questions related to the localization and function of Syt-7. The majority of the experiments in this study utilize chromaffin cells harvested from wild-type (WT) and Syt-7 knockout (KO) mice. First, we performed immunolabeling studies in dispersed mouse chromaffin cells to show that endogenous Syt-7 is primarily sorted to intracellular organelles (including dense core vesicles) rather than the plasma membrane. The role of Syt-7 in controlling the characteristics of exocytosis was inferred by monitoring - with TIRF microscopy the discharge of fluorescently labeled lumenal cargo proteins. Using this approach, we demonstrate that cells without Syt-7 release cargos at significantly faster rates than WT cells expressing a full complement of synaptotagmins. Consistent with data from overexpression studies $(12,13)$, this suggests that endogenous Syt-7 constrains rather than accelerates fusion pore expansion (11).

Importantly, we find that the absence of Syt-7 severely disrupts the ability of chromaffin cells to respond to cholinergic stimulation. In fact, the likelihood of observing fusion at all declines precipitously in KO cells after the first few seconds of stimulation with acetylcholine (ACh). In contrast, WT cells expressing a full complement of synaptotagmins continue to secrete even upon prolonged exposure to ACh. The ability of Syt-7 to sustain exocytosis even in the face of rapidly declining intracellular $\mathrm{Ca}^{2+}$ (i.e., after nicotinic receptor desensitization) is likely due to its high $\mathrm{Ca}^{2+}$ affinity. This idea is underscored by reconstitution studies in which dense core vesicles consisting of only Syt-1 or Syt-7 were triggered to fuse with synthetic bilayers. Even in this reduced setting, Syt-7-bearing vesicles fuse at significantly lower $\mathrm{Ca}^{2+}$ concentrations than Syt-1-bearing vesicles, with fusion pores that dilate at slower rates.

Taken together, our data highlight clear functional distinc- 
tions in the properties of synaptotagmins relevant to the physiological regulation of $\mathrm{Ca}^{2+}$-triggered exocytosis. The data suggest that in this system, as likely in others, isoforms may have diverged to fill different niches in the physiological regulation of $\mathrm{Ca}^{2+}$-triggered exocytosis.

\section{Materials and Methods}

Animals Litters of adult male and female Syt-7 -/- (gift of Dr. Joel Swanson; (14)) and +/+ (from a C57BL/6J background and obtained from Jackson Labs, Bar Harbor, ME) were used in these studies. Animals were group housed with $24 \mathrm{~h}$ access to food and water, 12/12 dark/light cycle. All animal procedures and experiments were conducted in accordance with the University of Michigan Institutional Animal Care and Use Committee.

Chromaffin cells preparation and transfection Below, we describe a novel method for the isolation and culture of adult mouse chromaffin cells from the adrenal medulla. Although the protocol was adapted from previous studies ((15), it is different enough to warrant a more detailed description. Animals were gas anesthetized using an isoflurane drop jar and sacrificed by guillotine decapitation (all procedures are in accordance with approved UM IACAC protocol PRO00007247). Six to eight adrenal glands/condition were rapidly isolated and moved to dishes containing ice cold dissection buffer $(148 \mathrm{mM} \mathrm{NaCl}, 2.57 \mathrm{mM} \mathrm{KCl}, 2.2 \mathrm{mM}$ $\mathrm{K}_{2} \mathrm{HPO}_{4} \cdot 3 \mathrm{H}_{2} \mathrm{O}, 6.5 \mathrm{mM} \mathrm{KH} \mathrm{PO}_{4}, 10 \mathrm{mM}$ glucose, $5 \mathrm{mM}$ HEPES free acid, $14.2 \mathrm{mM}$ manitol). Under a dissection microscope, the cortex was rapidly and carefully removed using thin forceps (Dumont Swissmade, Switzerland Cat. \# 72891$\mathrm{Bx}$ ) and thin micro scissors (World Precision Instruments, 14124-G). The isolated medullas were washed three times in three $150 \mu \mathrm{L}$ drops of enzyme solution containing (450 units/ml Papain (Worthington Biochemical \#LS003126), 250 $\mu \mathrm{g} / \mathrm{ml} \mathrm{BSA}$, and $75 \mu \mathrm{g} / \mathrm{ml}$ dithiothreitol). The medullas were then digested for 15 minutes in $0.5 \mathrm{ml}$ of the enzyme solution at $37^{\circ} \mathrm{C}$. After 15 minutes, the digesting solution was carefully removed and replaced by $0.5 \mathrm{ml}$ of fresh enzyme solution and left for a maximum of 15 extra minutes at $37^{\circ} \mathrm{C}$. The digestion was stopped by transferring the glands into an antibiotic-free culture medium (Dulbecco's Modified Eagle's Medium (DMEM) (ThermoFisher Scientific) supplemented with 10\% Fetal Bovine Serum (FBS) (ThermoFisher Scientific)). The digested glands were then triturated by a pushpull movement through a $1 \mathrm{ml}$ pipette tip (10 to 12 times). The supernatant was discarded, and the pellet re-suspended in antibiotic-free medium and triturated again in a $200 \mu \mathrm{l}$ pipette tip for a better cell dissociation $(10-12$ times). The suspension was spun again at $1300 \mathrm{x}$ g for $2.5 \mathrm{~min}$. After discarding the supernatant, the pellet was re-suspended in resuspension buffer (Invitrogen, Thermofisher Scientific) for transfection. The cells were rapidly counted and desired plasmid was added $\left(15 \mathrm{ng} / 10^{6}\right.$ cells). The suspended cells were then transiently transfected by electroporation with a single pulse $(1050 \mathrm{mV}, 40 \mathrm{~ms})$ using the Neon transfection system (Invitrogen, Thermofisher Scientific). In parallel, 35mm diameter dishes $14 \mathrm{~mm}$ glass-bottom dishes (MatTek Corpora- tion, Ashland, MA. \#P35G-1.5-14-C) were pre-coated with Matrigel (Corning, NY, Cat. \#356230) diluted in DMEM (1:7) for two hours after which the dishes were washed with DMEM and let to dry. After electroporation, an antibioticfree medium was added to cells to obtain a final concentration 1 million cells per ml. Three hundred microliters of the final solution containing the electroporated cells were then deposited in each dish. The cells were stored in an incubator $\left(37^{\circ} \mathrm{C}, 5 \% \mathrm{CO} 2\right)$ for three to five hours. Culture medium with antibiotics was then added to a final volume of $2 \mathrm{ml}$ (DMEM supplemented with $10 \%$ FBS, 9.52 unit/ml Penicillin, $9.52 \mu \mathrm{g} / \mathrm{ml}$ Streptomycin and $238 \mu \mathrm{g} / \mathrm{ml}$ Gentamicin (ThermoFisher Scientific)). The media was changed daily, and cells were used within 48 hours after plating. The method we describe here provides consistently healthy cells (Figure S1 which exhibit a high probability of secretion upon stimulation. Chromaffin cells were transfected with rat myc-Syt-7 or cargo proteins, including human Neuropeptide Y (NPY) and human tissue plasminogen activator (tPA). The myc-Syt7 plasmid was a gift of Dr. Thomas Südhof. The fluorescent tag was located following the C-terminal region of the cargo proteins. NPY and tPA constructs (originally in pEGFP-N1 vectors) were provided by Dr. Ronald W. Holz.

Western Blotting Lysis buffer containing 8M urea, 5\% SDS, and $5 \mathrm{mM}$ N-ethylmaleimide in water was heated to $65^{\circ} \mathrm{C}$. Adrenal glands were dissected from five months-old mice and immediately frozen in liquid nitrogen. Four total adrenal glands from two mice of each genotype were dissolved into $200 \mathrm{uL}$ of warm lysis buffer, and homogenized using a handheld, battery-operated homogenizer. The homogenate was incubated at $65^{\circ} \mathrm{C}$ for 20 minutes and mixed 1:1 with $5 x$ PAGE buffer $(5 \%$ (wt/vol) SDS, $25 \%$ (wt/vol) sucrose, 50mM Tris $\mathrm{pH} 8,5 \mathrm{mM}$ EDTA, and bromophenol blue). The lysates were stored at $-20^{\circ} \mathrm{C}$ until use. Samples (10uL/well) were separated on a 4-12\% NuPAGE Bis-Tris Gel in 1x NuPAGE MOPS SDS Running Buffer, for 1 hour at $175 \mathrm{mV}$. Transfer to nitrocellulose membrane occurred at $120 \mathrm{mV}$ for 1.5 hours, on ice, in 1x NuPAGE transfer buffer. The membrane was blocked with blocking buffer containing 5\% Bovine Serum Albumin (BSA) and 0.1\% tween in TBS (TBS-T) for 1 hour, before incubation with primary antibodies (Rabbit anti Synaptotagmin-7 1:1000, Synaptic Systems, and Mouse anti alpha-tubulin, 1:10,000, Cedarlane) at $4^{\circ} \mathrm{C}$, overnight. The membrane was washed $3 \times 15$ minutes with TBS-T and incubated for 1 hour with LiCor fluorescent secondaries $(1: 10,000)$ in blocking buffer (multiplexed). After washing 3x 15 minutes in TBS-T, the membrane was imaged using LiCor Odyssey Clx imager.

Reverse transcription and quantitative PCR Reverse transcription was performed on mouse adrenal medullas dissected from adrenal glands and homogenized. Adrenal medullas from two animals in each WT and Syt-7 KO group are considered as one experiment. Specifically, four adrenal medullas from two animals were homogenized in one 1.5$\mathrm{ml}$ Eppendorf tube on ice for $\sim 45$ seconds with motorized pestle mixer (Argos Technologies, Inc, Vernon Hills, IL). More than three experiments were performed for each tar- 
get. RNeasy Mini (Qiagen, Valencia, CA) was used to isolate the RNAs. The first strand cDNA synthesis was performed with 400 ng of RNAs using the qScript cDNA SuperMix kit (Quanta Biosciences, Beverly, MA). The reverse transcription product was kept at $-20^{\circ} \mathrm{C}$ until qPCR was performed. qPCR primers for the target genes were designed with online tools (GenScript PCR Primer Design and NCBI primer designing tool). The forward (fw) and reverse (rv) primer sequences are as follows: GAPDH fw CTGACGTGCCGCCTGGAGAA GAPDH rv CCCGGCATCGAAGGTGGAAGA Syt-1 fw GGCGCGATCTCCAGAGTGCT Syt-1 rv GCCGGCAGTAGGGACGTAGC Syt-7 fw CCAGACGCCACACGATGAGTC Syt-7 rv CCTTCCAGAAGGTCTGCATCTGG NPY fw GTGTGTTTGGGCATTCTGGC NPY rv TGTCTCAGGGCTGGATCTCT tPA fw CTCGGCCTGGGCAGACACAA tPA rv AGGCCACAGGTGGAGCATGG TH fw GCGCCGGAAGCTGATTGCAG TH rv CCGGCAGGCATGGGTAGCAT

Glyceraldehyde 3-phosphatedehydrogenase (GAPDH) was used as an endogenous control run in parallel with target genes. Each assay was performed in triplicate. For the qPCR, we used the PerfeCTa SYBR Green SuperMix (Quanta Biosciences, Beverly, MA). Ten ng of reverse transcription product was added to the master mix with $10 \mu \mathrm{M}$ of each primer. The directions for the PCR protocol were followed per the manufacturer's instructions. The qPCR was performed using the CFX96 TouchTM Real-Time PCR Detection System (Bio-Rad, Hercules, CA). Melting curves were analyzed to verify that no primer dimers were produced.

TIRF microscopy for observation of exocytosis TIRF imaging was performed using an Olympus cellTIRF-4Line microscope (Olympus, USA) equipped with a TIRF oilimmersion objective (NA 1.49) and an additional $2 x$ lens in the emission path between the microscope and the cooled electron-multiplying charge-coupled device Camera (iXon 897; Andor Technology). The final pixel size of the images was $80 \mathrm{~nm}$. Series of images were acquired at $20 \mathrm{~Hz}$ using CellSense software with an exposure time of $30 \mathrm{~ms}$ and an EM gain of 100. pHl and GFP were excited using a $488 \mathrm{~nm}$ laser.

Cell stimulation All TIRF experiments were performed at room temperature $24^{\circ} \mathrm{C}$. The culture medium was replaced by pre-warmed $\left(37^{\circ} \mathrm{C}\right)$ physiological salt solution (PSS) (145 $\mathrm{mM} \mathrm{NaCl}, 5.6 \mathrm{mM} \mathrm{KCl}, 2.2 \mathrm{mM} \mathrm{CaCl} 2,0.5 \mathrm{mM} \mathrm{MgCl} 2$, $5.6 \mathrm{mM}$ glucose, and $15 \mathrm{mM}$ HEPES, $\mathrm{pH}$ 7.4). Chromaffin cells were individually stimulated using a needle $(100-\mu \mathrm{m}$ inner diameter) connected to a perfusion system under positive pressure ALA-VM4 (ALA Scientific Instruments, Westbury, NY). To trigger exocytosis, cells were first perfused with PSS for $5-10 \mathrm{~s}$ and then stimulated with high potassium containing solution $(100 \mathrm{mM} \mathrm{KCl})$ for $70-75 \mathrm{~s}$. For the acetylcholine experiment, $100 \mu \mathrm{M}$ acetylcholine (Sigma-Aldrich) diluted in PSS was perfused for $120 \mathrm{~s}$.

Image analysis Fusion sites of vesicles containing GFP or pHl-tagged proteins undergoing exocytosis were identified. Regions of interest (ROIs) measuring $0.8 \mu \mathrm{m}$ diameter were manually selected at fusion sites and image sequences were analyzed using the Time Series Analyzer v3.0 plugin on Fiji software. For each ROI, the fluorescence intensity was measured for each frame. A nearby ROI of the same size where no fusion events were observed was selected for background subtraction. Using a custom program written in Interactive Data Language (IDL; ITT, Broomfield, CO) by Dr. Daniel Axelrod (University of Michigan), background subtracted intensity versus time curves were plotted and the duration of cargo release was calculated. Briefly, a start time was determined by the user on the intensity versus time curves shortly before the rise of the fluorescence. The end time was determined as the point at which the intensity reaches its lowest level after the decline of the signal. The duration of release is obtained via fitting the curve between the start and end time with a weighted fifth degree polynomial. This method is described in details elsewhere (16). Each fusion event was further analyzed by the user to confirm that only events in which cargos were completely released were used in the analysis.

Cells transfected with GCaMP5g were analyzed to determine the relative amount of calcium influx into the cell. Three ROIs measuring $1.68 \mu \mathrm{m}$ diameter were manually selected at different points within each cell and fluorescence was measured for each ROI for each frame. The equation $\Delta \mathrm{F} / \mathrm{F}$ was applied to each ROI for each frame, then the values were averaged between the three ROIs to determine the overall $\Delta \mathrm{F} / \mathrm{F}$ for the whole cell. The values determined were plotted versus time. The exclusion criteria used to select which cells to analyze were based on proper fixation to the dish, no response to the control stimulation, and single response tracings that indicated calcium influx in response to the stimulus trigger.

Immunocytochemistry Immunofluorescence imaging was performed to assess the distribution of endogenous Syt-1, Syt-7 and PAI-1 in chromaffin cells. Mouse chromaffin cells were plated on the same Matrigel-precoated $14 \mathrm{~mm}$ glassbottom dishes used for TIRF imaging. All incubations and washing steps were performed on ice unless otherwise stated. Twenty-four hours after plating, the cells were fixed with $4 \%$ paraformaldehyde in phosphate buffered solution (PBS) for $30 \mathrm{~min}$. The fixed cells were quickly rinsed with PBS and quenched with $50 \mathrm{mM} \mathrm{NH} 4 \mathrm{Cl}$ solution in PBS for $30 \mathrm{~min}$. After a brief wash from the $\mathrm{NH} 4 \mathrm{Cl}$ solution with PBS, the cells were permeabilized with methanol for $7 \mathrm{~min}$ at $-20^{\circ}$ C. Following the permeabilization, the cells were washed in Tris-buffered saline (TBS) and blocked in $0.01 \%$ gelatin solution for 30 minutes followed by another $30 \mathrm{~min}$ incubation in $4 \%$ donkey serum and $0.2 \%$ bovine serum albumin (BSA) prepared in TBS. Primary and secondary antibodies were diluted in TBS at $0.2 \%$. Cells were incubated for two hours with a combination of polyclonal rabbit anti-Syt-7 antibody (Synaptic Systems, Göttingen, Germany. Cat \# 105 173, 1:1200), and monoclonal mouse anti-Syt-1 (Synaptic Systems, Göttingen, Germany. Cat \# 105 011, 1:1200). The cells were then washed and incubated for 70 minutes at room temperature with Alexa 488/561-conjugated anti-rabbit and anti-mouse secondary antibodies (Molecular Probes, Invitrogen). The double labeled cells were then washed and kept a $4^{\circ} \mathrm{C}$ until confocal imaging. For co-labeling of endoge- 
nous PAI-1 and Syt-7, both the polyclonal anti-Syt-7 and polyclonal anti-PAI-1 (Abcam cat\# 66705) antibodies were made in rabbit. In this experiment, to avoid cross-labeling, the cells were first labeled with anti-Syt-7 following the protocol described above. Cells labeled for Syt-7 were then incubated for 60 minutes with polyclonal cross-adsorbed unconjugated F(ab')2-Goat anti-Rabbit IgG (Invitrogen, ThermoFisher, Cat. \# A24539, 1:300) diluted in TBS-0.2\% BSA solution to bind the possibly remaining free primary antibody sites (anti-Syt-7) not bound by the Alexa 488-conjugated Donkey anti-rabbit. Labeling for PAI-1 was performed separately. Briefly, the primary and secondary antibodies (antiPAI1, 1:600 - Alexa 561-conjugated anti rabbit, 1:600) were incubated for 70 minutes in reaction tube pre-adsorbed in dry milk $1 \%$ diluted in TBS (17). After incubation, normal rabbit serum (Invitrogen, ThermoFisher Scientific, Cat. \# 016101) was added to the tube ( $10 \%$ volume/volume dilution) to bind the free secondary antibody for 60 minutes. The mix was then added in the Syt-7 labeled dishes for two hours. In control dishes, either the Syt-7 or PAI-1 antibodies were omitted (Figure S2) to verify the absence of cross-labeling. Cells were subsequently imaged using a Zeiss 880 confocal microscope (Zeiss, Oberkochen, Germany) with a 63x oil immersion objective in airyscan mode. Images were analyzed using Imaris Software (Bitplane, Zurich, Switzerland) using the "spot" function module for puncta detection and colocalization analysis (12). Cells were subsequently imaged using a Zeiss 880 confocal microscope (Zeiss, Oberkochen, Germany) with a $63 x$ oil immersion objective in airyscan mode. Images were analyzed using Imaris Software (Bitplane, Zurich, Switzerland) using the "spot" function module for puncta detection and colocalization analysis (12).

Electrophysiological recordings Primary cultures of mouse chromaffin cells were maintained on glass bottom dishes and mounted onto the stage of a Nikon Eclipse TE2000, as previously described (12). A micro-manifold and polyamidecoated capillary was positioned in the field of view and bath solutions were exchanged through using a pressure-driven reservoir system. Standard whole-cell patch clamp methods were used record currents evoked by acetylcholine or by step depolarizations using an Axopatch 200B amplifier and Pulse Control/Igor Pro software. Patch pipettes were constructed out of $1.5 \mathrm{~mm}$ o.d. borosilicate glass (\#TW150F-4; WPI, Sarasota, FL), coated with Sylgard elastomer and fire polished to resistances of 2.5-7 M $\Omega$. The standard intracellular recording solution contained (in $\mathrm{mM}$ ): $128 \mathrm{~N}$-methyld-glucamine-Cl, 40 HEPES, $10 \mathrm{NaCl}, 4 \mathrm{Mg}$-ATP, $0.2 \mathrm{GTP}$, 0.1 Tris-EGTA, and $\mathrm{pH}$ adjusted to 7.2. $\mathrm{I}_{\mathrm{Ach}}$ were induced by $10 \mathrm{~s}$ to $300 \mathrm{~s}$ applications of $100 \mu \mathrm{M} \mathrm{ACh}$ and recorded in physiological saline $(125 \mathrm{mM} \mathrm{NaCl}, 2.5 \mathrm{mM} \mathrm{KCl}, 2 \mathrm{mM}$ $\mathrm{CaCl}_{2}, 1 \mathrm{mM} \mathrm{MgCl}_{2}, 1.25 \mathrm{mM} \mathrm{NaH}_{2} \mathrm{PO}_{4}, 26 \mathrm{mM} \mathrm{NaHCO}_{3}$, and $25 \mathrm{mM}$ glucose, $\mathrm{pH}$ 7.4). For recording of $\mathrm{I}_{\mathrm{Ca}}$, the superfusion solution was changed to a solution containing (in $\mathrm{mM}$ ): 137 tetraethylammonium chloride, $5 \mathrm{CaCl}_{2}, 2 \mathrm{MgCl}_{2}$, 10 HEPES, and 19 glucose, and $\mathrm{pH}$ adjusted to 7.2 with Tris. $\mathrm{I}_{\mathrm{Ca}}$ current-voltage relationship was obtained in response to step depolarizations $(30 \mathrm{~ms}$ ) from a holding membrane po- tential of $-90 \mathrm{mV}$. Pulses were applied in a randomized series to membrane potentials between -80 and $+60 \mathrm{mV}$. All recordings were performed at room temperature.

Materials and Methods for Single vesicle/supported membrane fusion assay The following materials were purchased and used without further purification: porcine brain L- $\alpha$-phosphatidylcholine (bPC), porcine brain L$\alpha$-phosphatidylethanolamine (bPE), porcine brain L- $\alpha$ phosphatidylserine (bPS), and L- $\alpha$-phosphatidylinositol (liver, bovine) (PI), and porcine brain phosphatidylinositol 4,5-bisphosphate $\left(\mathrm{bPIP}_{2}\right)$ were from Avanti Polar Lipids; cholesterol, sodium cholate, EDTA, calcium, Opti-Prep Density Gradient Medium, sucrose, MOPS, glutamic acid potassium salt monohydrate, potassium acetate, and glycerol were from Sigma; CHAPS and DPC were from Anatrace; HEPES was from Research Products International; chloroform, ethanol, Contrad detergent, all inorganic acids and bases, and hydrogen peroxide were from Fisher Scientific. Water was purified first with deionizing and organic-free 3 filters (Virginia Water Systems) and then with a NANOpure system from Barnstead to achieve a resistivity of 18.2 $\mathrm{M} \Omega / \mathrm{cm}$. Antibodies for synaptotagmin-1 (mouse monoclonal), synaptotagmin-7 (rabbit polyclonal) are from Synaptic Systems.

PC12 Cell Culture Pheochromocytoma cells (PC12) with endogenous synaptotagmin-1 and -9 knocked down, described previously (18), were cultured on $10-\mathrm{cm}$ plastic cell culture plates at $37 \mathrm{OC}$ in $10 \% \mathrm{CO}_{2}$ in 1x Dulbecco's modified Eagle's medium, high glucose (Gibco) supplemented with $10 \%$ horse serum (CellGro), 10\% calf serum (Fe+) (HyClone), $1 \%$ penicillin/streptomycin mix, and $2 \mu \mathrm{g} / \mathrm{ml}$ of puromycin. Medium was changed every 2 to 3 days and cells were passed after reaching $90 \%$ confluency by incubating for 5 minutes in Hank's balanced salt solution and replating in fresh medium. Cells were transfected by electroporation using ECM 830 Electro Square Porator (BTX). After harvesting and sedimentation, cells were suspended in a small volume of sterile cytomix electroporation buffer $(120 \mathrm{mM} \mathrm{KCl}$, $10 \mathrm{mM}$ KH2PO4, $0.15 \mathrm{mM} \mathrm{CaCl} 2,2 \mathrm{mM}$ EGTA, $20 \mathrm{mM}$ HEPES-KOH, $5 \mathrm{mM} \mathrm{MgCl}$, $2 \mathrm{mM}$ adenosine triphosphate, and $5 \mathrm{mM}$ glutathione (pH 7.6), then diluted to $\sim 14 \times 10^{6} / \mathrm{ml}$. Cell suspensions ( $\sim 10 \times 10^{6}$ in $700 \mu \mathrm{l}$ volume) and $30 \mu \mathrm{g}$ of NPY-mRuby DNA and $30 \mu \mathrm{g}$ of synaptotagmin- 1 or -7 DNA added and placed in an electroporator cuvette with a 4-mm gap. Then two 255-V, 8-ms electroporation pulses were applied. Cells were immediately transferred to a $10-\mathrm{cm}$ cell culture dish with $10 \mathrm{ml}$ of normal growth medium. Cells were cultured under normal conditions for 3 days prior to fractionation.

Dense core vesicle purification Dense core vesicles from PC12 cells were purified as described previously (18). PC12 cells with shRNA mediated knockdowns of endogenous synaptotagmin-1 and -9 were transfected with NPY-mRuby ( $2010-\mathrm{cm}$ plates) and plasmids for synaptotagmin-1 or -7 $(18,19)$. Cells were scraped into PBS and pelleted by centrifugation and then suspended and washed in homogenization medium ( $0.26 \mathrm{M}$ sucrose, $5 \mathrm{mM}$ MOPS, $0.2 \mathrm{mM}$ EDTA) 
by pelleting and re-suspending. Following re-suspension in $3 \mathrm{ml}$ of medium containing protease inhibitor (Roche Diagnostics), the cells were cracked open using a ball bearing homogenizer with a 0.2507 -inch bore and 0.2496-inch diameter ball. The homogenate was spun at 4,000 rpm for 10 minutes at $4 \mathrm{o} \mathrm{C}$ in fixed-angle micro-centrifuge to pellet nuclei and larger debris. The post-nuclear supernatant was collected and spun at $11,000 \mathrm{rpm}(8000 \mathrm{x} \mathrm{g})$ for $15 \mathrm{~min}$ at $4 \mathrm{o} \mathrm{C}$ to pellet mitochondria. The post-mitochondrial supernatant was then collected, adjusted to $5 \mathrm{mM}$ EDTA, and incubated $10 \mathrm{~min}$ on ice. A working solution of 50\% Optiprep (iodixanol) (5 vol 60\% Optiprep: 1 vol $0.26 \mathrm{M}$ sucrose, $30 \mathrm{mM}$ MOPS, 1 mM EDTA) and homogenization medium were mixed to prepare solutions for discontinuous gradients in Beckman SW55 tubes: $0.5 \mathrm{ml}$ of $30 \%$ iodixanol on the bottom and $3.8 \mathrm{ml}$ of $14.5 \%$ iodixanol, above which $1.2 \mathrm{ml}$ EDTA-adjusted supernatant was layered. Samples were spun at 45,000 rpm $(190,000 \mathrm{x} \mathrm{g})$ for $5 \mathrm{hrs}$. A clear white band at the interface between the $30 \%$ iodixanol and the $14.5 \%$ iodixanol was collected as the dense core vesicle sample. The dense core vesicle sample was then extensively dialyzed in a cassette with $10,000 \mathrm{kD}$ molecular weight cutoff ( $24-48 \mathrm{~h}, 3 \times 5 \mathrm{~L})$ into the fusion assay buffer (120 mM potassium glutamate, $20 \mathrm{mM}$ potassium acetate, $20 \mathrm{mM}$ HEPES, $\mathrm{pH}$ 7.4).

Protein purification Synataxin-1a (constructs of residues 1288), SNAP-25, Munc18, and Munc13 (construct of residues 529-1407 containing the C1C2MUN region), and complexin1 from Rattus norvegicus were expressed in Escherichia coli strain BL21(DE3) cells described previously (18-20).

Formation of planar supported bilayers with reconstituted plasma membrane SNAREs Planar supported bilayers with reconstituted plasma membrane SNAREs were prepared by Langmuir-Blodgett/vesicle fusion technique as described in previous studies (21-23). Quartz slides were cleaned by dipping in 3:1 sulfuric acid:hydrogen peroxide for 15 minutes using a Teflon holder. Slides were then rinsed in milli-Q water. The first leaflet of the bilayer was prepared by Langmuir-Blodgett transfer onto the quartz slide using a Nima 611 Langmuir-Blodgett trough (Nima, Conventry, UK) by applying the lipid mixture of 70:30:3 bPC:Chol:DPS from a chloroform solution. Solvent was allowed to evaporate for 10 minutes, the monolayer was compressed at a rate of $10 \mathrm{~cm} 2 /$ minute to reach a surface pressure of $32 \mathrm{mN} / \mathrm{m}$. After equilibration for 5 minutes, a clean quartz slide was rapidly $(200 \mathrm{~mm} /$ minute $)$ dipped into the trough and slowly $(5 \mathrm{~mm} /$ minute) withdrawn, while a computer maintained a constant surface pressure and monitored the transfer of lipids with head groups down onto the hydrophilic substrate. Plasma membrane SNARE containing proteoliposomes with a lipid composition of bPC:bPE:bPS:Chol:PI:PI(4,5)P2 (25:25:15:30:4:1) were prepared by mixing the lipids and evaporating the organic solvents under a stream of $\mathrm{N} 2$ gas followed by vacuum desiccation for at least 1 hour. The dried lipid films were dissolved in $25 \mathrm{mM}$ sodium cholate in a buffer (20 mM HEPES, 150 $\mathrm{mM} \mathrm{KCl}, \mathrm{pH}$ 7.4) followed by the addition of an appropriate volume of synatxin-1a and SNAP-25 in their respective de- tergents to reach a final lipid/protein ratio of 3,000 for each protein. After 1 hour of equilibration at room temperature, the mixture was diluted below the critical micellar concentration by the addition of more buffer to the desired final volume. The sample was then dialyzed overnight against $1 \mathrm{~L}$ of buffer, with one buffer change after $\sim 4$ hour with Biobeads included in the dialysis buffer. To complete formation of the SNARE containing supported bilayers, proteoliposomes were incubated with the Langmuir-Blodgett monolayer with the proteoliposome lipids forming the outer leaflet of the planar supported membrane and most SNAREs oriented with their cytoplasmic domains away from the substrate and facing the bulk aqueous region. A concentration of $\sim 77 \mathrm{mM}$ total lipid in $1.2 \mathrm{ml}$ total volume was used. Proteoliposomes were incubated for 1 hour and excess proteoliposomes were removed by perfusion with $5 \mathrm{ml}$ of buffer $(120 \mathrm{mM}$ potassium glutamate, $20 \mathrm{mM}$ potassium acetate $(20 \mathrm{mM}$ potassium sulfate was used in buffers with acridine orange labeled vesicles), 20 mM HEPES, $100 \mu \mathrm{M}$ EDTA, pH 7.4).

TIRF microscopy for single vesicle/supported membrane fusion assay Dense core vesicle to planar supported bilayer fusion assay experiments were performed on a Zeiss Axio Observer 7 fluorescence microscope (Carl Zeiss), with a 63x water immersion objective (Zeiss, N.A. 0.95) and a prismbased TIRF illumination. Laser light at $514 \mathrm{~nm}$ from an argon ion laser (Innova 90C, Coherent), controlled through an acousto-optic modulator (Isomet), and at $640 \mathrm{~nm}$ from a diode laser (Cube 640, Coherent) were used as excitation sources. The characteristic penetration depths were between 90 and $130 \mathrm{~nm}$. An OptoSplit (Andor Technology) was used to separate two spectral bands $(540 \mathrm{~nm}-610 \mathrm{~nm}$, and 655 $\mathrm{nm}-725 \mathrm{~nm}$ ). Fluorescence signals were recorded by an EMCCD (iXon DV887ESC-BV, Andor Technology).

Calcium-triggered single vesicle - planar supported membrane fusion assay As previously described (18), planar supported bilayers containing syntaxin-1a (1-288): dodecylated (d) SNAP-25 (bulk phase-facing leaflet lipid composition of 25:25:15:30:4:1 bPC:bPE:bPS:Chol:PI:bPIP ${ }_{2}$ ) were incubated with $0.5 \mu \mathrm{M}$ Munc18 and $2 \mu \mathrm{M}$ complexin-1. Secretory vesicles were then injected while keeping the concentrations of Munc18 and complexin-1 constant. Dense core vesicle docking was allowed to occur for 20 minutes before the chamber was placed on the TIRF microscope and the microscope was focused on the planar supported membrane. Fluorescent images were recorded every $200 \mathrm{~ms}$ while buffer containing $100 \mu \mathrm{M}$ calcium and a soluble Alexa647 dye to monitor the arrival of calcium at the observation site was injected.

Movies were analyzed as previously described (18, 24, 25). Fusion efficiencies are reported as the percentage of vesicles in the field of view that fuse within $15 \mathrm{~s}$. Fluorescent line shapes are presented as average from 20 single events as described previously (25).

\section{Results}

Syt-1 and Syt-7 exhibit a non-overlapping distribution in mouse chromaffin cells Fluorescent labeling of endogenous 
Synaptotagmin 1 and 7 in bovine adrenal chromaffin cells revealed these proteins to exhibit a punctate intracellular distribution, with a low degree of co-localization (13). A similar pattern is observed in chromaffin cells harvested from the mouse adrenal medulla. As shown in Figure 1, endogenous Syt-1 and Syt-7 fluorescence is largely non-overlapping (in the range of $3-5 \%$ ), punctate, and intracellular. It was previously reported that Syt-7 is sorted to the plasma membrane in PC12 cells and rat chromaffin cells (8). However, the punctate pattern of staining we observe is most consistent with the protein being sorting to organelles. The frequent colocalization with PAI-1 (Figure 1 C, D) - a dense core marker in chromaffin cells (16) - shows that Syt-7 is also sorted to secretory vesicles.
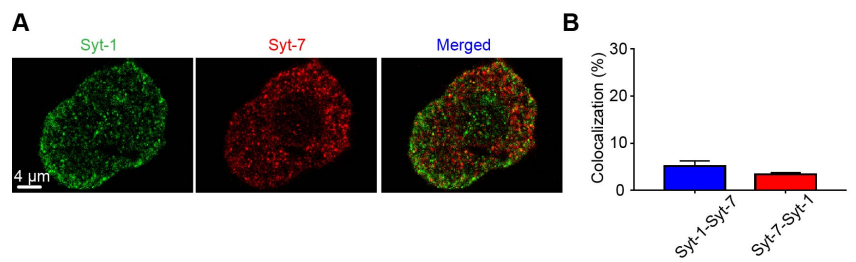

C
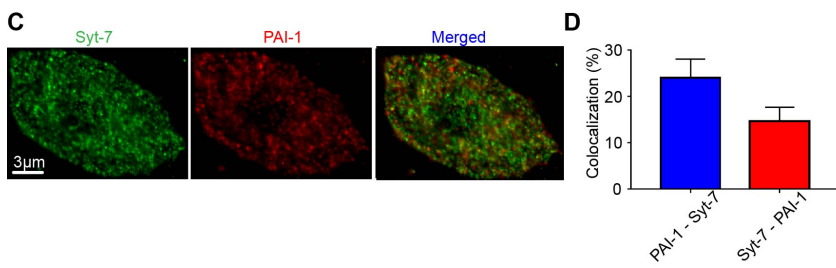

Fig. 1. Endogenous Syt-7 is co-localized with PAI-1, a protein of the vesicle dense core. A. Immunolabeling was performed in WT cells for endogenous Syt-7 (red) and Syt-1 (green). Images from a representative cell showing Syt-7 fluorescence, Syt-1 fluorescence, and fluorescence of the merged channels. B. Bar graphs indicate the percentage of Syt-1 puncta that harbor Syt-7 $(5.18 \pm 1.03 \% ; n=8$ cells $)$ and Syt-7 puncta that harbor Syt-1 (3.36 $\pm 0.43 \% ; n=8$ cells). C. Immunolabeling was performed in WT cells for Syt-7 (green) and PAI-1, a dense core vesicle marker (red). D. Bar graphs showing the percentage of PAI-1 puncta that are co-localized with Syt-7 (24.06 $\pm 1.41 \% ; n=8$ cells) and the percentage of Syt-7 puncta that are co-localized with PAI-1 (14.65 $\pm 1.075 \% ; n=8$ cells).

Endogenous Syt-7 slows dense core vesicle cargo release A major goal of this study was to delineate the ways in which the chromaffin cell secretory system depends on the presence of Syt-7. To avoid the potential ambiguities associated with overexpression of synaptotagmins in cells already expressing a full complement of endogenous proteins, most of the experiments in this study instead rely on cells harvested from Syt-7 KO mice. Figure S3A shows that compared to WT cells, expression of Syt-1 transcript is not different from WT cells, while Syt-7 transcript is almost undetectable. We also performed a Western Blot on adrenal gland lysates to verify the loss of Syt-7 protein in the KO. The alpha variant of Syt7 (403 amino acids), targeted by Norma Andrews and colleagues when generating the original Syt-7 KO mouse, has been reported to run at approximately $45 \mathrm{kD}$ (marked by arrow) (14). That band is absent in the KO (Figure S3B).

We previously showed that dense core vesicle cargo proteins NPY and Chromogranin B $(\mathrm{CgB})$ were released more slowly from vesicles harboring overexpressed Syt-7 than overexpressed Syt-1 (13). Therefore, we predicted cargo release rates would be, on average, slower from WT mouse chro-
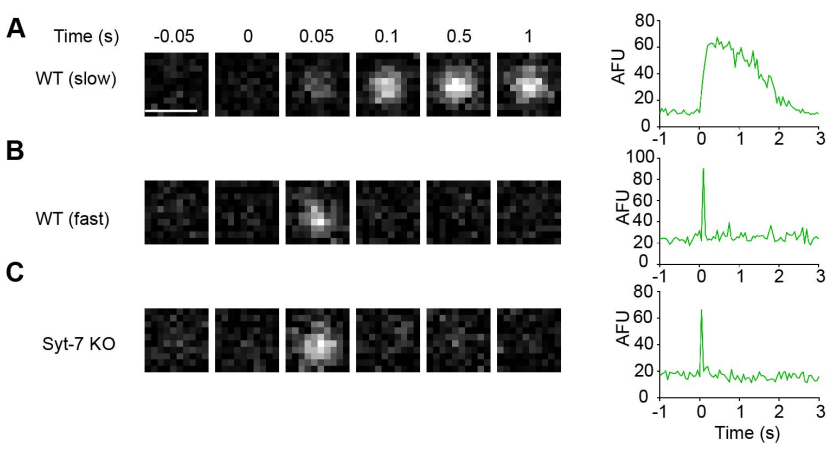

D

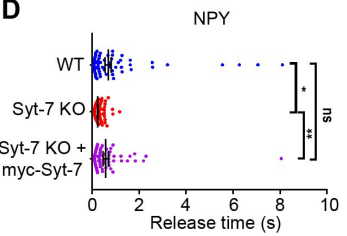

E

tPA

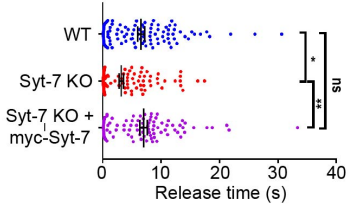

Fig. 2. Syt-7 slows release of lumenal cargos.WT and Syt-7 KO cells overexpressing $\mathrm{pH}$-tagged NPY and tPA were stimulated with $100 \mathrm{mM} \mathrm{KCl}$. Fusion events were observed using TIRFM and cargo release time was measured. A-C.. Representative images showing fusion events of NPY-pHI expressing vesicles from WT and Syt- $7 \mathrm{KO}$ chromaffin cells alongside intensity vs. time curves. Release times in WT cells ranged from fast to slow (A). However, release times in Syt-7 KO cells were more consistently fast (C). D. Release times for individual NPY events shown in a scatter plot. Release times in WT cells ranged from $49 \mathrm{~ms}$ to $8.10 \mathrm{~s}$ (average time $=0.67 \pm 0.13 \mathrm{~s} ; \mathrm{n}=100$ events). In Syt-7 KO cells, the distribution of the release times was narrower, and ranged from $84 \mathrm{~ms}$ to $1.17 \mathrm{~s}$ (average time $=0.23 \pm 0.01$ $\mathrm{s} ; \mathrm{n}=130$ events). The overexpression of myc-Syt-7 in Syt-7 KO cells restored the broader distribution of release times, which now ranged from $76 \mathrm{~ms}$ to $8.05 \mathrm{~s}$ (average time $=0.57 \pm 0.11 \mathrm{~s} ; n=77$ events). E. Release times for individual tPA events shown in a scatter plot. Secretion events from WT cells show a large distribution of release time ranging from $68 \mathrm{~ms}$ to $30.67 \mathrm{~s}$ (average time $=6.57 \pm 0.59 \mathrm{~s} ; \mathrm{n}=$ 103 events). In Syt-7 KO cells, the distribution of the release time was somewhat narrower, and ranged from $84 \mathrm{~ms}$ to $17.44 \mathrm{~s}$ (average time $=3.16 \pm 0.38 \mathrm{~s} ; \mathrm{n}=$ 120 events). The overexpression of myc-Syt-7 in the Syt-7 KO cells again restored the broader distribution of release times, which now ranged from $100 \mathrm{~ms}$ to $33.4 \mathrm{~s}$ (average time $=7.00 \pm 0.62 \mathrm{~s} ; \mathrm{n}=89$ events). ${ }^{*} p<0.05,{ }^{* *} \mathrm{p}<0.005$ Tukey's multiple comparison test.

maffin cells than those that lacked Syt-7. To test this idea, we overexpressed NPY-pHl in WT and KO cells. Cells expressing fluorescent protein were identified by a brief exposure to $10 \mathrm{mM} \mathrm{NH} 4 \mathrm{Cl}$ (26). Single cells were then depolarized by local perfusion of $100 \mathrm{mM} \mathrm{KCl}$ while exocytosis was imaged with a TIRF microscope. Figures $2 \mathrm{~A}, \mathrm{~B}$, and D show that the time necessary for NPY to be completely released from fused chromaffin vesicles is broadly distributed in WT cells (times ranged from $0.049 \mathrm{~s}$ to $8.10 \mathrm{~s}$ ). In Syt-7 KO cells. NPY release durations were shifted to shorter times (ranging from $0.084 \mathrm{~s}$ to $1.17 \mathrm{~s}$ ) (Figure $2 \mathrm{C}$ and D). To confirm that Syt-7 was responsible for the slower events, rates of NPY release were also measured in KO cells co-expressing myc-tagged Syt-7 and NPY-pHluorin (myc expression was verified post hoc). In cells where Syt-7 expression was restored, NPY release times were were slowed (times ranged from $0.076 \mathrm{~s}$ to $8.05 \mathrm{~s}$ ) (Figure 2D).

Certain lumenal cargo proteins, such as tissue Plasminogen Activator (tPA), exhibit intrinsically slower release or "discharge" times during exocytosis $(27,28)$ In the case of tPA, this has been attributed to the protein's ability to stabilize the curvature of the fusion pore and thereby limit its rate of expansion (16). Here, we wanted to address whether tPA re- 
lease from fused vesicles may be hastened by the abrogation of Syt-7 expression - a protein which imposes its own constraints on fusion pore expansion $(12,13)$. As before, the rate of release of tPA-pHl was measured in both WT and Syt$7 \mathrm{KO}$ cells depolarized with $\mathrm{KCl}$. We found that the average rate at which IPA is released is considerably slower than it is for NPY (tPA: $6.57 \pm 0.59 \mathrm{~s}$, NPY: $0.67 \pm 0.13 \mathrm{~s}$, Mann Whitney test, $\mathrm{p}<0.0001$ ) (Figure $2 \mathrm{E}$ ). In fact, this is consistent with what has been reported in the bovine system by Holz and colleagues (16). As with NPY, release times for tPA were more broadly distributed in WT cells (times ranged $0.068 \mathrm{~s}$ to $30.67 \mathrm{~s}$ in WT cells) compared to Syt-7 KO cells (times ranged from $0.084 \mathrm{~s}$ to $17.44 \mathrm{~s}$ ) in which, again, the slowest events were absent. Overexpression of myc-Syt-7 in Syt-7 KO cells restored these slow events. These data support the idea that Syt-7 imposes limits on the rate at which cargos are discharged during exocytosis. In the case of cargos within an intrinsically slow release profile, the effect of Syt-7 is additive.

Vesicle fusion probability is impaired in cells lacking Syt7. Syt-7 binds $\mathrm{Ca}^{2+}$ and anionic phospholipids more avidly than Syt-1. The higher in vitro $\mathrm{Ca}^{2+}$ sensitivity of Syt-7 (2931 ) is reflected in its cellular actions. Vesicles bearing overexpressed GFP-tagged Syt-7 evince a higher fusion probability in response to $\mathrm{KCl}$ depolarization than vesicles bearing GFP-tagged Syt-1 $(12,13,32)$. Therefore, one would predict that the fusion probability of docked vesicles in cells lacking Syt-7 would be lower than in WT cells expressing both isoforms. We tested this hypothesis by depolarizing WT and $\mathrm{KO}$ cells with elevated external $\mathrm{KCl}$ and calculating the fusion probability of docked NPY-GFP (Figure 3A). The fu-
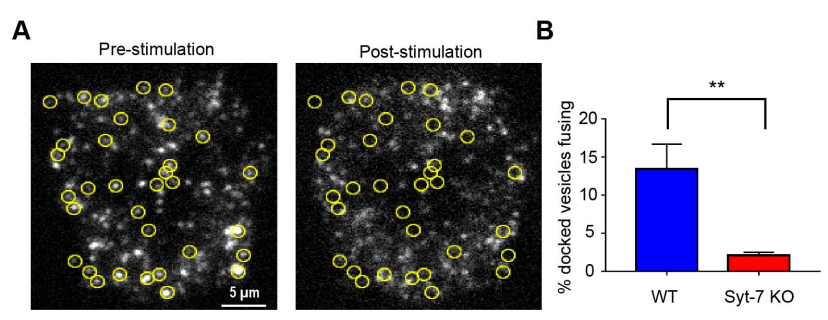

Fig. 3. Syt-7 endows vesicles with an increased fusion probability. WT and Syt-7 KO cells overexpressing GFP-tagged NPY were stimulated with $100 \mathrm{mM} \mathrm{KCl}$. Fusion events were observed using TIRFM. A. Pre- and post-stimulation images of fluorescent NPY puncta in a WT cell. Yellow circles indicate the position of vesicles that fused during the stimulation period. B. Bar graphs showing the percentage of docked vesicles that fused in WT $(13.49 \pm 3.23 \% ; n=8)$ and Syt-7 KO cells $(2.14$ $\pm 0.36 \mathrm{~s} ; \mathrm{n}=5) .{ }^{* *} \mathrm{p}<0.005$, Mann-Whitney test.

sion probability of vesicles in WT cells exhibited at least a 5 -fold higher fusion probability than vesicles in cells lacking Syt-7 exposed to the same stimulus (Figure 3B).

We also examined another aspect of granule behavior in mouse chromaffin cells - namely, whether vesicles in KO cells exhibit the same or an altered degree of mobility than those in WT cells. These experiments were motivated by data in the bovine system showing vesicles harboring GFP-Syt-7 to be less mobile than those harboring GFP-Syt-1 (12). Here, we obtained xy tracks of vesicles only expressing endogenous Syt-1 (KO cells) and compared them to those of vesicles harboring Syt-1 and/or Syt-7 (WT cells) (Figure S4A and B). As before, NPY-GFP was used to identify vesicles. Each vesicle included in the analysis had tracks of at least 200 frames ( $10 \mathrm{~s}$ in duration). From those tracks, we calculated frame-to-frame displacement $(\Delta \mathrm{R})$ of individual vesicles (Figure S4C). The distribution of $\Delta$ Rs for vesicles from both vesicle types were best fit to a sum of two gaussians, with the WT vesicles obviously being comprised of more than one population. The average $\Delta \mathrm{R}$ from the slower wild type population was $29.32+/-1.41 \mathrm{~nm}$, and $48.39+/-1.13$ $\mathrm{nm}$ for the faster population, with $53.58+/-30.67 \%$ of vesicles residing in the slower population. The differences between the slower and faster populations of $\mathrm{KO}$ vesicles were much less pronounced, with a slow population $\Delta \mathrm{R}$ of 27.82 $+/-0.59$, a fast population $\Delta \mathrm{R}$ of $39.97+/-3.76$, and $47.84+/-$ $59.77 \%$ of vesicles residing in the slower population. There is not a clear correspondence between these data and those in bovine cells in which synaptotagmin isoforms were overexpressed. However, the studies are consistent in demonstrating that chromaffin cells contain multiple populations of vesicles that evince different degrees of mobility.

Stimulation of secretion in WT and Syt-7 KO cells with a physiological agonist Chromaffin cell secretion, in situ, is triggered by activation of nicotinic receptors and subsequent $\mathrm{Ca}^{2+}$ influx $(33,34)$. Therefore, to understand how the lack of Syt-7 might disrupt secretion in a physiological setting, we stimulated WT and KO cells with ACh delivered locally via a perfusion pipet. We first measured ACh-triggered release kinetics of NPY-pHl (Figure 4A-D). As with elevated $\mathrm{KCl}$

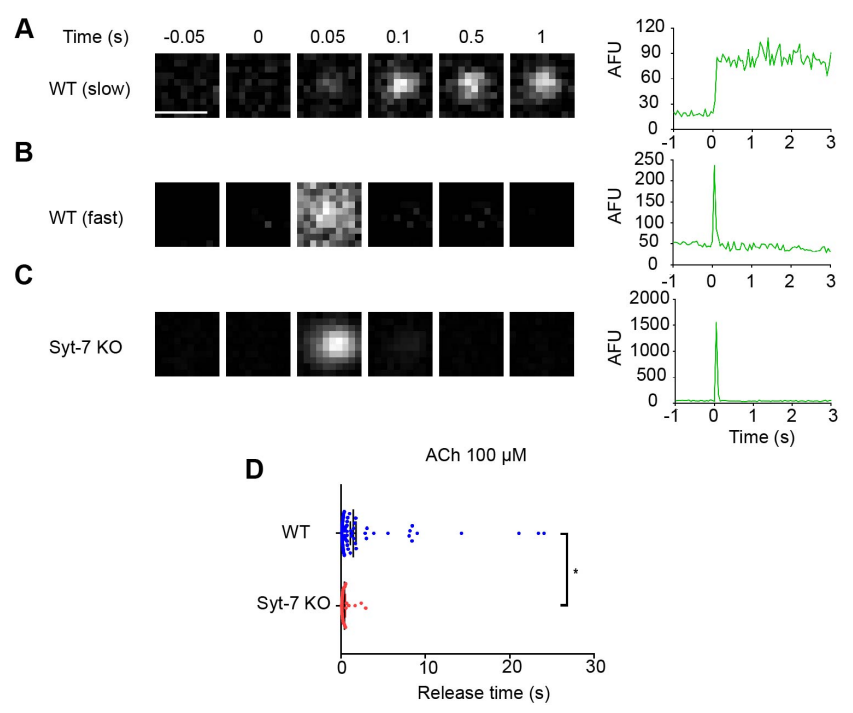

Fig. 4. Syt-7 slows release of overexpressed NPY in cells stimulated with ACh. WT and Syt-7 KO cells overexpressing NPY were stimulated with ACh $(100 \mu \mathrm{M})$ for two minutes. Fusion events were monitored using TIRFM and NPY release times were measured. A-C. Representative images showing fusion events from WT and Syt-7 KO chromaffin cells alongside intensity vs. time curves. Release times in WT cells ranged from fast to slow (A). Release times in Syt-7 KO cells were typically faster (C). D. Release times for individual NPY fusion events shown in a scatter plot. Release times in WT cells ranged from $67 \mathrm{~ms}$ to $24.05 \mathrm{~s}$ (average time $=1.47$ $\pm 0.34 \mathrm{~s} ; \mathrm{n}=130,7$ cells). In Syt- $7 \mathrm{KO}$ cells, the distribution of the release times was narrower and ranged from $70 \mathrm{~ms}$ to $2.93 \mathrm{~s}$ (average time $=0.44 \pm 0.10 \mathrm{~s}$ ( $\mathrm{n}=$ 38, 9 cells).

stimulation, the range of NPY release times in response to ACh stimulation was broader in WT cells $(0.06 \mathrm{~s}$ to $24.05 \mathrm{~s})$ than in Syt-7 KO ( $0.07 \mathrm{~s}$ to $2.93 \mathrm{~s}$ ) cells. On average, the rate 
at which NPY is released was slower in WT cells compared to Syt-7 KO cells (WT: $1.47 \pm 0.34 \mathrm{~s}$, KO: $0.44 \pm 0.1 \mathrm{~s}$, Mann Whitney test, $\mathrm{p}<0.05$ ) (Figure 5D). Moreover, the overall fusion probability of vesicles in Syt-7 KO cells was substantially lower than WT cells following cholinergic stimulation $(3.2 \pm 0.7 \% \mathrm{KO}$ versus $19.1 \pm 3.4 \%$, respectively) (Figure $4 \mathrm{~A}, \mathrm{~B})$. One potential explanation for the difference in vesi-
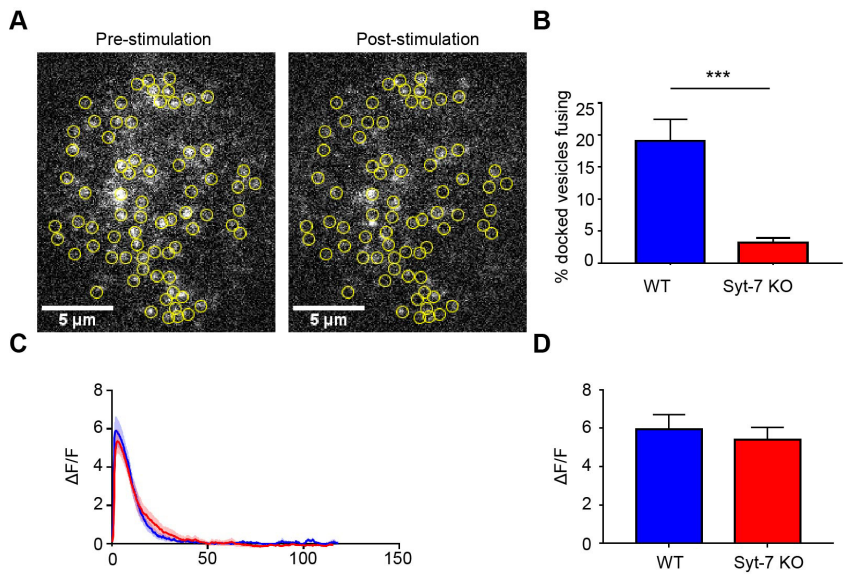

Fig. 5. Vesicles in Syt-7 KO cells exhibit a lower fusion probability than those in WT cells in response to ACh stimulation. WT and Syt-7 KO cells overexpressing GFP-tagged NPY were stimulated with a $100 \mu \mathrm{M}$ ACh solution. Fusion events were observed using TIRFM. A. Pre- and post-stimulation images of fluorescent NPY puncta in a WT cell. Yellow circles indicate the position of vesicles that fused during the stimulation period. B. Bar graphs showing the percentage of docked vesicles fused in WT $(19.1 \pm 3.4 \% ; n=8)$ and Syt-7 KO $(3.2 \pm 0.7 \% ; n=$ 7). ${ }^{* \star *} p<0.005$, Mann-Whitney test. C-D. WT and Syt-7 KO cells transfected with GCaMP5g were stimulated with ACh $(100 \mu \mathrm{M})$ for two minutes. The GCaMP signal was monitored using TIRFM, and $\triangle F / F$ was calculated for each cell. C. Average $\Delta \mathrm{F} / \mathrm{F}$ vs. time traces in response to ACh stimulation for $\mathrm{WT}(\mathrm{n}=7$, blue) and Syt-7 $\mathrm{KO}(\mathrm{n}=7$, red) cells. D. Bar graphs showing the average value of the peak $\Delta \mathrm{F} / \mathrm{F}$ for WT $(5.41 \pm 0.62)$ and Syt-7 KO (5.94 \pm 0.76$)$ cells. The average values were not statistically significant (Student's t-test, $p>0.05$ )

cle fusion probability observed between the two cell types is that $\mathrm{Ca}^{2+}$ signaling is compromised in cells lacking Syt-7. Therefore, we measured qualitative changes in intracellular $\mathrm{Ca}^{2+}$ in response to ACh-stimulation using the fluorescent amplitude of the gCaMP5g signal differed between WT and Syt-7 KO cells (Figure 5C, D). We also tested the possibility that differences in the amplitude of cholinergic or $\mathrm{Ca}^{2+}$ currents might underlie differences in the secretory phenotype of WT and KO cells. As shown in Figures 6A-D, neither of these explanations can account for the lower fusion probability of vesicles in Syt-7 KO cells. Thus, the most parsimonious explanation is that the lack of Syt-7 protein is principally responsible for the impaired secretory response of $\mathrm{KO}$ chromaffin cells. presence of Syt-7 During the course of the experiments described in Figure 4, we observed that there were kinetic differences between the fusion times of vesicles in WT and KO cells. To examine this issue more directly, we overexpressed NPY-pHl in chromaffin cells and stimulated secretion via a two minute perfusion of $100 \mu \mathrm{M}$ ACh. The secretory response of a single WT and Syt-7 KO cell to prolonged ACh stimulation (beginning at $5 \mathrm{~s}$ after imaging begins) is shown $\mathrm{Ca}^{2+}$ indicator, gCaMP5g. Neither the kinetics nor the peak

Sustained chromaffin cell secretory output relies on the

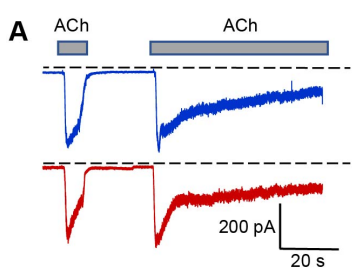

B

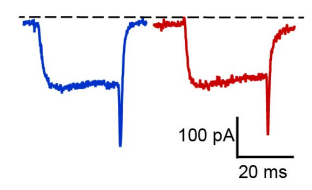

C

D

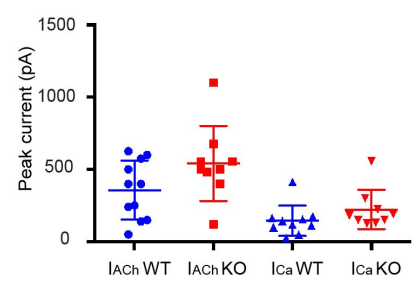

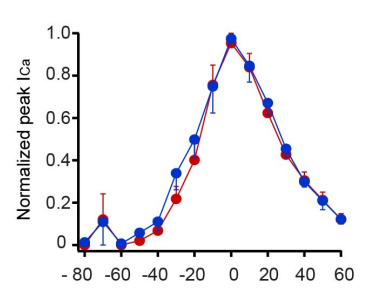

Fig. 6. Cholinergic currents and depolarization-evoked $\mathrm{Ca}^{2+}$ currents are similar in WT and KO cells. Whole-cell patch clamp recordings were performed in WT (Blue) and Syt-7 KO (red) cells. A-B. Representative cholinergic currents $\left(\mathrm{I}_{\mathrm{ACh}} ; \mathrm{A}\right)$ and $\mathrm{Ca}^{2+}$ currents $\left(\mathrm{I}_{\mathrm{Ca}} ; \mathrm{B}\right)$. Currents were evoked by application of 100 $\mu \mathrm{M}$ ACh $(\mathrm{A})$ or by a $30 \mathrm{~ms}$ step-depolarization (B) from a holding potential of -90 $\mathrm{mV}$. C. Voltage-dependent activation and inactivation of the $\mathrm{I}_{\mathrm{Ca}}$ in WT and Syt-7 KO cells. Each point represents the mean peak amplitude of the $\mathrm{I}_{\mathrm{Ca}}(n=7)$ evoked by a 30 ms step depolarization to test potentials of different amplitudes from a holding potential of $-90 \mathrm{mV}$ and normalized to the maximal response of each cell. D. A comparison of the mean data and range of peak amplitudes of $\mathrm{I}_{\mathrm{Ach}}$ and $\mathrm{I}_{\mathrm{Ca}}$ evoked in WT and Syt-7 KO cells. Mean Syt-7 KO current amplitudes were not altered compared to WT cells (Student's t-test, $p>0.05$ ).

in Figures 7A and B. Each of the vertical lines (blue for WT and red for KO) corresponds to the time of an individual NPY fusion event over the course of ACh exposure. In the example shown, fusion events in a WT cell continue throughout the course of stimulation. On the other hand, the secretory response rapidly wanes in the $\mathrm{KO}$ cell after an initial burst of fusion events. We plotted the cumulative distribution of all fusion events in WT and Syt-7 KO cells ( $\mathrm{n}=7$ cells for each group) occurring after ACh exposure (Figure 7C). A distinctive feature of the cumulative time course for Syt-7 KO events is that the curve plateaus. Such a feature is consistent with the idea that Syt-7 is necessary for a sustained response to cholinergic stimulation. The cumulative time course for WT cells stimulated with ACh does not plateau; secretion persists for as long as the cell is stimulated. The curves could be fit by the sum of two exponential functions representing the fast and slow/sustained phases of secretion. The fast phase, in WT cells, is a minor component of the curve $(0.66 \%)$, whereas the slow phase dominates. In the Syt-7 KO, the fast phase of release constitutes a greater proportion of the span of the curve $(58.08 \%)$ than the slow phase. Interestingly, over the first approximately $20 \mathrm{~s}$ of ACh stimulation, there is more secretory activity in the Syt-7 KO than in the WT cell (see inset, Figure 7C). This faster phase of release may reflect the fact that Syt-1 no longer has to compete with Syt-7 for fusion sites.

Syt-7 endows dense core vesicles with distinct $\mathrm{Ca}^{2+}$. sensing and fusion properties The most straightforward interpretation of our data to this point is that Syt-7 acts directly from the vesicle membrane to endow dense core vesicles with an increased fusion probability and to slow the rate of fu- 
A

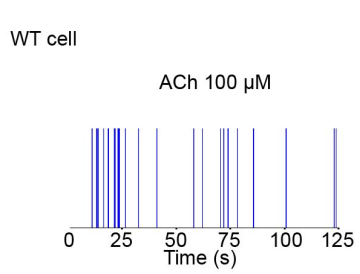

B KO cell

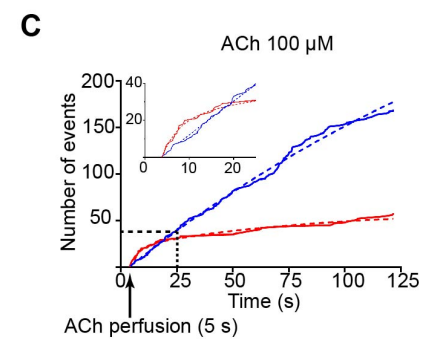

Fig. 7. Syt-7 is necessary to sustain secretion during prolonged ACh stimulation. WNPY-pHI was overexpressed in WT and Syt-7 KO chromaffin cells. Secretion was triggered by local perfusion of $100 \mu \mathrm{M}$ ACh. A-B. Time distribution of fusion events in a WT (A) and Syt-7 KO (B) cell. Each line corresponds to the occurrence of a single fusion event during the stimulation period. C. Cumulative frequency distribution showing the time at which fusion events occured in WT (blue) and Syt-7 KO (red) cells ( $n=7$ for each group). WT cells continue to secrete throughout the course of the stimulation period; secretory activity in Syt-7 KO cells largely ceases after $25 \mathrm{sec}$. Note that in the $5 \mathrm{~s}-25 \mathrm{~s}$ window (inset), the rate at which fusion events occur is actually higher in the Syt-7 $\mathrm{KO}$ cell. Curves were fit by a two phase association function in Prism 7 with $R^{2} \geq 0.99 ; \mathrm{WT}$ : $\mathrm{k}_{\text {fast }}=1.3 \mathrm{~s}^{-1} ; \mathrm{k}_{\text {slow }}=$ $4.3 \times 10-3 \mathrm{~s}^{-1} ; \mathrm{KO}: \mathrm{k}_{\text {fast }}=0.26 \mathrm{~s}^{-1} ; \mathrm{k}_{\mathrm{slow}}=1.3 \times 10-2 \mathrm{~s}^{-1}$.

sion pore dilation. An alternative possibility, not yet ruled out, is that the functions we have attributed to Syt-7 represent the collaborative efforts of multiple proteins on the fusion pore, with Syt-7 having a secondary role. To better assign mechanistic roles to Syt-1 and Syt-7 in exocytosis, we utilized a previously characterized purified secretory vesicle to planar supported bilayer fusion assay (Figure 8A). PC12 cells lacking endogenous synaptotagmin (18) were transfected to overexpress either Syt-1 or Syt-7 protein ((19) and Figure 8B). In the presence of SNARE regulatory proteins Munc18 and complexin-1, these vesicles will bind in an arrested state to planar supported bilayers (lipid composition of 70:30 bPC:Chol in the extracellular mimicking leaflet and 25:25:15:30:4:1 bPC:bPE:bPS:Chol:PI:PIP ${ }_{2}$ ) containing the plasma membrane SNARE proteins (syntaxin1a and dSNAP-25). Injection of $\mathrm{Ca}^{2+}$ into this system readily stimulates fusion of dense core vesicles with the planar bilayer - a process which is visualized with TIRF microscopy. Injecting increasing amounts of $\mathrm{Ca}^{2+}$ into the chamber containing docked dense core vesicles, triggers fusion with different efficiencies depending on the sensitivity to $\mathrm{Ca}^{2+}$ of the expressed synaptotagmin isoform (Figure 8C). Syt-7 containing dense core vesicles consistently fused at lower $\mathrm{Ca}^{2+}$ concentrations than those bearing Syt-1. The higher sensitivity of Syt-7 bearing vesicles to $\mathrm{Ca}^{2+}$ is consistent with the observation in cells that mild depolarization selectively activates Syt-7 containing vesicles $(12,13,32)$. The intensity time course of NPY-mRuby fluorescence during release has noteworthy characteristics. Initially, a decrease in fluorescence is observed as NPY-mRuby begins to diffuse out of the early fusion pore and away from the fusion site (note dip in fluorescence in Figures 8D and 8E). After a brief delay, a sharp increase in fluorescence intensity is observed as the fusion pore expands and the vesicle membrane collapses (18). Previously, the delay time from the onset of NPY-mRuby release was shown to be sensitive to the presence of lipids with geometries that promote or inhibit fusion pore stability (25). Here, we show this feature is also sensitive to the synaptotagmin isoform expressed. A close examination of the fluorescence intensity profile of Syt-1 vesicles shows that there is approximately a $0.4 \mathrm{~s}$ delay time from the initial decrease in fluorescence until the collapse of the vesicle into the supported bilayer (Figure 8D). In Syt-7 vesicles, this delay is approximately $1 \mathrm{~s}$ (Figure 8E). The reconstituted fusion assay confirms at least two predictions based on previous studies in chromaffin cells $(12,13,32)$. First, we predicted that vesicles bearing Syt-7 will fuse at lower $\mathrm{Ca}^{2+}$ concentrations compared to those bearing Syt-1, as the likelihood of Syt-1 or Syt-7 vesicle fusion strongly corresponded to the strength of cellular stimulation. In the in vitro reconstitution assay, we observe that Syt-7-bearing vesicles exhibit a higher fusion probability across a wide range of $\mathrm{Ca}^{2+}$ concentrations, up to $100 \mathrm{mM} \mathrm{Ca}^{2+}$ (Figure $8 \mathrm{C}$ ). A second prediction, also confirmed, was that Syt-7 has the potential to impose effects on the open fusion pore that distinguish it from Syt-1. This may be because Syt-7 actively slows expansion (32), or alternatively, does not accelerate expansion to the same degree as Syt-1.

\section{Discussion}

Despite the broad interest in Syt-7 as a regulator of exocytosis (1), surprisingly basic aspects of its function remain unresolved. Here, we attempted to address some of these issues in the context of the chromaffin cell secretory response. There are several important findings with respect to this goal worth emphasizing. In terms of subcellular localization, we report that endogenous Syt-7 is primarily intracellular and frequently co-localized with PAI-1, consistent with its sorting to dense core vesicles. This result is similar to what has been published by others with respect to Syt-7 localization in PC12 cells as well as primary chromaffin cells $(9,10,35,36)$. In contrast, neuronal Syt-7 has been reported to exist primarily as a plasma membrane bound protein $(8,37,38)$. The reason for this discrepancy in Syt-7 localization between neurons and neuroendocrine cells is unclear. One possible scenario is that there are differences in the sorting pathways targeting Syt-7 to its eventual subcellular destination in distinct cell types. A number of possibilities exist with respect to the nature of those sorting pathways (1). Post-translational protein modifications such as glycosylation and palmitoylation have previously been shown to be important for proper sorting of some certain synaptic proteins $(1,39,40)$. In fact, disrupting Syt-7 palmitoylation within macrophages abrogates its trafficking to lysosomes (41).

An unresolved question concerning the function of Syt-7 in chromaffin cells is whether it constrains, or alternatively, promotes fusion pore expansion. We previously reported that overexpressed Syt-7 stabilizes the fusion pore (13). Ac- 
A

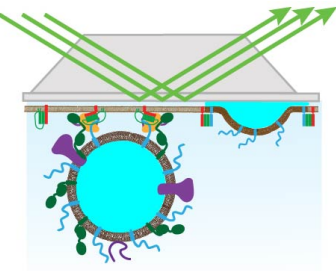

B

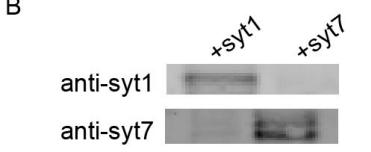

C

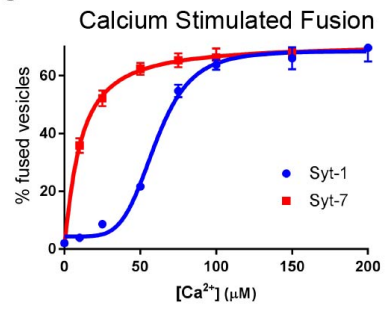

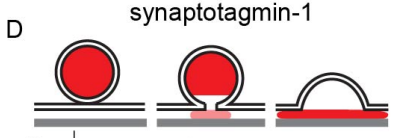

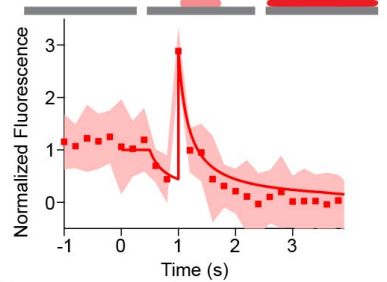

E

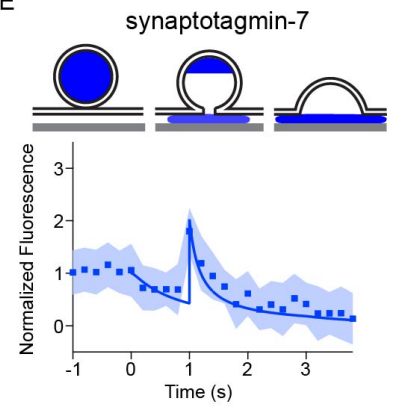

Fig. 8. In vitro fusion of Syt-7 and Syt-1 vesicles on planar supported bilayers. A-B. Fusion of dense core vesicles containing either Syt-1 or Syt-7 with planar supported bilayers containing syntaxin-1a, dSNAP-25, Munc18, and complexin-1 were examined. As previously described, dense core vesicles labeled with NPYmRuby stably dock to the supported bilayer, where fusion is triggered by injection of calcium. C. The calcium sensitivity of fusion is dependent on the Syt-isoform expressed on purified dense core vesicles $\left(\mathrm{K}_{1 / 2}=63 \pm 3 \mu \mathrm{M}\right.$ for Syt-1 vesicles and $10 \pm 1 \mu \mathrm{M}$ for Syt-7 vesicles). Example of a characteristic NPY-mRuby signal DE. is observed for fusion. There is an initial decrease in NPY-mRuby fluorescence caused by diffusion of the protein away from the site of fusion under the cleft of the supported bilayer. This is followed by an increase in fluorescence caused by a collapse of the vesicle into the supported bilayer. This action pulls the remaining lumenal content towards the brightest portion of the evanescent field. Eventually, the fluorescence diminishes as NPY-mRuby diffuses away from the site of fusion. Averaging more than 20 individual traces (D, E) for Syt-1 fusion events, revealed a short delay (D) between the initial decrease in fluorescence and the subsequent increase in fluorescence during vesicle collapse. The delay time between these phases of the fluorescent signal was prolonged for Syt-7 vesicle fusion. The cartoons illustrate the mathematical model (solid line in $C$ and $D$ ) used to fit the data.

cordingly, vesicle cargos in Syt-7-bearing vesicles were discharged with slower kinetics than those associated with Syt1-bearing vesicles (32). A recent study by Zhuan Zhou and colleagues posits an alternative scenario, where Syt-7 promotes rather than inhibits fusion pore expansion (11). Here, we used two distinct experimental preparations to address this issue, including primary mouse chromaffin cells lacking Syt-7 and a reconstituted single vesicle fusion assay employing vesicles only expressing one synaptotagmin isoform at a time. Both sets of experiments point to the same conclusion - that Syt-7 retards the rate at which fusion pores expand and thereby slows lumenal cargo release. We note that our findings are also consistent with TIRF-based measurements of secretion in other systems, including mouse embryonic fibroblasts, where it was shown that Syt-7 restricts post-fusion soluble content release and diffusion of vesicle membrane proteins into the plasma membrane (42). It should also be noted that multiple cellular effectors have been identified to modify fusion pore properties including some acting from the cytosol (dynamin, Epac2, myosin II etc.) (5, 43-47) and others acting from within the vesicle itself $(16,28,48)$. Thus, it is very likely that Syt-7 cooperates with other proteins to modify the properties of release in ways that are not yet clear. Nevertheless, the work here points to a role for Syt-7 that is at least as important as those of the other effectors referenced above.

Much of our earlier work on the synaptotagmins has been performed in the bovine chromaffin cell system. We note here that a significant difference between the bovine and mouse preparations is that $25 \mathrm{mM} \mathrm{KCl}$ - a "mild" stimulus we previously used to evoke secretion in bovine chromaffin cells fails to evoke secretion with any consistency in the mouse chromaffin cells (not shown). Instead, it was necessary to use $100 \mathrm{mM} \mathrm{KCl}$ to obtain an analyzable number of fusion events; this concentration of $\mathrm{KCl}$ was previously at the strong end of our stimulation regime (12). Note, that neither 100 $\mathrm{mM} \mathrm{KCl}$ nor $100 \mu \mathrm{M}$ ACh is as effective in evoking secretion in Syt-7 KO cells as in WT cells. The greater likelihood of observing fusion events in WT cells is not due to impaired $\mathrm{Ca}^{2+}$ "handling" or excitability in Syt-7 KO cells. Instead, we attribute the deficiency in the secretory response to the absence of the high affinity $\mathrm{Ca}^{2+}$-sensor. This hypothesis is supported by the observation that there is effectively no difference in the magnitude of $\mathrm{Ca}^{2+}$ or cholinergic current in WT versus KO chromaffin cells (Figure 6). Moreover, the dose-response curves in Figure $8 \mathrm{C}$ show that there is at least a 6-fold difference in the $\left[\mathrm{Ca}^{2+}\right]_{1 / 2}$ for fusion of purified dense core vesicles bearing Syt-1 $(63 \mu \mathrm{M})$ versus Syt-7 (10 $\mu \mathrm{M})$. In fact, at $10 \mu \mathrm{M} \mathrm{Ca}^{2+}$, there is no appreciable fusion of Syt-1 vesicles.

The presence of both Syt-7 and Syt-1 is necessary for an effective secretory response to a range of intracellular $\mathrm{Ca}^{2+}$ levels, from low to high. This is evident from experiments showing that the ability of chromaffin cells to sustain secretory output is compromised in the absence of Syt-7 (Figure 7). In Figure 9, we propose a mechanism to explain why such an outcome might be observed. Over the course of a twominute exposure to $\mathrm{ACh}$, nicotinic receptors undergo densensitization (Figure 6A). Free cytosolic $\mathrm{Ca}^{2+}$, initially elevated as a result of $\mathrm{Ca}^{2+}$ influx through nAChRs, and also possibly Cavs, is rapidly sequestered, buffered, or extruded (49). Despite the collapse of the $\mathrm{Ca}^{2+}$ gradient, fusion persists in WT cells throughout the period of ACh perfusion (Figure 9B, C). On the other hand, in Syt-7 KO cells, secretory activity quickly ceases after an initial burst of fusion. Thus, we conclude that expression of Syt-7 is necessary for sustained activity in the face of rapidly declining levels of intracellular free $\mathrm{Ca}^{2+}$ following $\mathrm{nAChR}$ desensitization. Presumably, the residual $\mathrm{Ca}^{2+}$ that remains is effective at triggering fusion (note as well the distinct $\mathrm{Ca}^{2+}$ dose-response curves for fusion of dense core vesicles (Figure 8C)) are likely sufficient to account for this phenomenon.

The assertion that the initial and later phases of exocytosis have different $\mathrm{Ca}^{2+}$ sensitivities is supported by previous work by Holz and colleagues in permeabilized bovine chromaffin cells (50). By measuring $[3 \mathrm{H}]$ norepinephrine in the medium after cells were exposed to different levels of $\mathrm{Ca}^{2+}$, M. A. Bittner and R. W. Holz (50) concluded that an early 
A

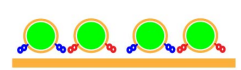

B

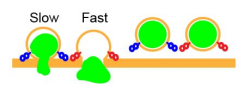

C
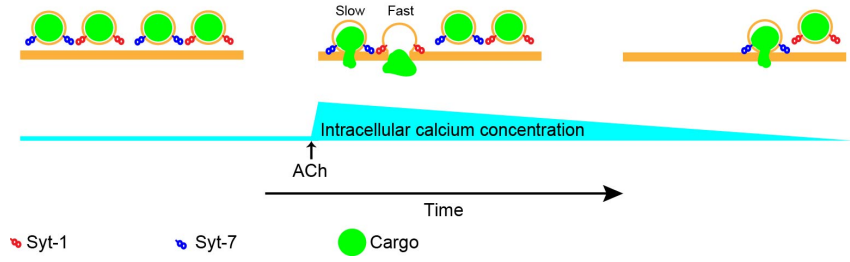

Fig. 9. Chromaffin cells require Syt-7 for sustained secretory activity during cholinergic stimulation. A-B. Chromaffin cell vesicles harbor Syt-1, Syt-7, or both (not shown). When stimulated with ACh, intracellular calcium concentrations increase rapidly (Figure $5 \mathrm{C}$ ), leading to fusion of Syt-1 and Syt-7 vesicle populations. C. Prolonged stimulation with ACh causes nicotinic desensitization. Associated with desensitization is a corresponding decline in intracellular $\mathrm{Ca}^{2+}$ which is buffered, sequestered, or otherwise removed from the cytosol (Figures $5 \mathrm{C}$ and 6 A). Because Syt-1 has a lower affinity for $\mathrm{Ca}^{2+}$ than Syt-7, vesicles bearing this isoform are less likely to fuse as intracellular $\mathrm{Ca}^{2+}$ levels decline. On the other hand Syt-7-bearing vesicles continue to fuse even with diminished free cytosolic $\mathrm{Ca}^{2+}$.

phase of release (i.e., occurring with $5 \mathrm{~s}$ of stimulation) must correspond to a lower affinity process $\left(\left[\mathrm{Ca}^{2+}\right]_{1 / 2}\right.$ of approximately $100 \mu \mathrm{M}$ ) than a later phase of release (i.e., occurring between $5-10 \mathrm{~s}\left(\left[\mathrm{Ca}^{2+}\right]_{1 / 2}\right.$ of approximately $\left.\left.10 \mu \mathrm{M}\right)\right)$. In this study, we attribute a molecular mechanism to their observation based on the sequential activation of specialized low and high affinity $\mathrm{Ca}^{2+}$ sensors.

To conclude, the experiments in this study demonstrate that the absence of Syt-7 has a profound impact on the $\mathrm{Ca}^{2+}$. triggering of secretion from chromaffin cells. It is, therefore, somewhat surprising that the global Syt-7 KO mouse does not present any overt phenotypic disturbances. At least in the context of the adrenal medulla, we would predict that there should physiological consequences to the lack of Syt-7. But it may be that, in the $\mathrm{KO}$, compensatory mechanisms exist to ensure adequate delivery of hormones to peripheral organs to maintain homeostasis. Even in this scenario, it seems likely that physiological disturbances will become evident if a system without Syt-7 is challenged with the appropriate stressor. Exactly what form that stressor should take, however, is not yet established.

\section{ACKNOWLEDGEMENTS}

The authors thank Drs. J. David Castle and Ronald W. Holz for critical reading of the manuscript. This study was supported by NIH grants R01GM111997 to A.A. and P01GM072694 to L.K.T. A.C-M. and J.M.P. are supported by a fellowship from the Pharmacological Sciences Training Program T32GM007767 at the University of Michigan.

\section{Bibliography}

1. D. D. MacDougall, Z. Lin, N. L. Chon, S. L. Jackman, H. Lin, J. D. Knight, and A. Anantharam. The high-affinity calcium sensor synaptotagmin-7 serves multiple roles in regulated exocytosis. J Gen Physiol, 150(6):783-807, 2018. ISSN 1540-7748 (Electronic) 0022-1295 (Linking). doi: 10.1085/jgp.201711944.

2. P. K. Moghadam and M. B. Jackson. The functional significance of synaptotagmin diversity in neuroendocrine secretion. Front Endocrinol (Lausanne), 4:124, 2013. ISSN 1664-2392 (Print) 1664-2392 (Linking). doi: 10.3389/fendo.2013.00124.

3. S. W. Carmichael and H. Winkler. The adrenal chromaffin cell. Sci Am, 253(2):40-9, 1985. ISSN 0036-8733 (Print) 0036-8733 (Linking).

4. A. M. de Diego, L. Gandia, and A. G. Garcia. A physiological view of the central and peripheral mechanisms that regulate the release of catecholamines at the adrenal medulla. Acta Physiol (Oxf), 192(2):287-301, 2008. ISSN 1748-1716 (Electronic) 1748-1708 (Linking). doi: $10.1111 / \mathrm{j} .1748-1716.2007 .01807 . x$

5. Tiberiu Fulop, Stephen Radabaugh, and Corey Smith. Activity-dependent differential transmitter release in mouse adrenal chromaffin cells. Journal of Neuroscience, 25(32):73247332, 2005.

6. M. Wang, Q. Wang, and M. D. Whim. Fasting induces a form of autonomic synaptic plasticity that prevents hypoglycemia. Proc Natl Acad Sci U S A, 113(21):E3029-38, 2016. ISSN 1091-6490 (Electronic) 0027-8424 (Linking). doi: 10.1073/pnas.1517275113.

7. J. S. Schonn, A. Maximov, Y. Lao, T. C. Sudhof, and J. B. Sorensen. Synaptotagmin-1 and -7 are functionally overlapping ca2+ sensors for exocytosis in adrenal chromaffin cells. Proc Natl Acad Sci U S A, 105(10):3998-4003, 2008. ISSN 1091-6490 (Electronic) 0027-8424 (Linking). doi: 10.1073/pnas.0712373105.

8. S. Sugita, W. Han, S. Butz, X. Liu, R. Fernandez-Chacon, Y. Lao, and T. C. Sudhof. Synaptotagmin vii as a plasma membrane ca(2+) sensor in exocytosis. Neuron, 30(2):459-73, 2001. ISSN 0896-6273 (Print) 0896-6273 (Linking).

9. M. Fukuda, E. Kanno, M. Satoh, C. Saegusa, and A. Yamamoto. Synaptotagmin vii is targeted to dense-core vesicles and regulates their ca2+-dependent exocytosis in pc12 cells. J Biol Chem, 279(50):52677-84, 2004. ISSN 0021-9258 (Print) 0021-9258 (Linking). doi: $10.1074 /$ jbc.M409241200.

10. T. Tsuboi and M. Fukuda. Synaptotagmin vii modulates the kinetics of dense-core vesicle exocytosis in pc12 cells. Genes Cells, 12(4):511-9, 2007. ISSN 1356-9597 (Print) 13569597 (Linking). doi: 10.1111/j.1365-2443.2007.01070.x.

11. Q. Zhang, B. Liu, Q. Wu, B. Liu, Y. Li, S. Sun, Y. Wang, X. Wu, Z. Chai, X. Jiang, X. Liu, M. Hu, Y. Wang, Y. Yang, L. Wang, X. Kang, Y. Xiong, Y. Zhou, X. Chen, L. Zheng, B. Zhang, C. Wang, F. Zhu, and Z. Zhou. Differential co-release of two neurotransmitters from a vesicle fusion pore in mammalian adrenal chromaffin cells. Neuron, 102(1):173-183 e4, 2019. ISSN 1097-4199 (Electronic) 0896-6273 (Linking). doi: 10.1016/j.neuron.2019.01.031.

12. T. C. Rao, Z. S. Rodriguez, M. M. Bradberry, A. H. Ranski, P. J. Dahl, M. W. Schmidtke, P. M. Jenkins, D. Axelrod, E. R. Chapman, D. R. Giovannucci, and A. Anantharam. Synaptotagmin isoforms confer distinct activation kinetics and dynamics to chromaffin cell granules. Journal of General Physiology, 149(8):763-780, 2017. ISSN 0022-1295. doi: 10.1085/jgp.201711757.

13. T. C. Rao, D. R. Passmore, A. R. Peleman, M. Das, E. R. Chapman, and A. Anantharam. Distinct fusion properties of synaptotagmin-1 and synaptotagmin-7 bearing dense core granules. Mol Biol Cell, 25(16):2416-27, 2014. ISSN 1939-4586 (Electronic) 1059-1524 (Linking). doi: 10.1091/mbc.E14-02-0702.

14. I. Martinez, S. Chakrabarti, T. Hellevik, J. Morehead, K. Fowler, and N. W. Andrews. Synaptotagmin vii regulates $\mathrm{ca}(2+)$-dependent exocytosis of lysosomes in fibroblasts. J Cell Biol, 148(6):1141-49, 2000. ISSN 0021-9525 (Print) 0021-9525 (Linking).

15. A. Kolski-Andreaco, H. Cai, D. S. Currle, K. G. Chandy, and R. H. Chow. Mouse adrenal chromaffin cell isolation. J Vis Exp, (2):129, 2007. ISSN 1940-087X (Electronic) 1940-087X (Linking). doi: 10.3791/129.

16. K. P. Bohannon, M. A. Bittner, D. A. Lawrence, D. Axelrod, and R. W. Holz. Slow fusion pore expansion creates a unique reaction chamber for co-packaged cargo. J Gen Physiol, 149 (10):921-934, 2017. ISSN 1540-7748 (Electronic) 0022-1295 (Linking). doi: 10.1085/jgp. 201711842.

17. S. Kroeber, C. Schomerus, and H. W. Korf. A specific and sensitive doubleimmunofluorescence method for the demonstration of $s$-antigen and serotonin in trout and rat pinealocytes by means of primary antibodies from the same donor species. Histochem Cell Biol, 109(4):309-17, 1998. ISSN 0948-6143 (Print) 0948-6143 (Linking).

18. A. J. B. Kreutzberger, V. Kiessling, B. Liang, P. Seelheim, S. Jakhanwal, R. Jahn, J. D. Castle, and L. K. Tamm. Reconstitution of calcium-mediated exocytosis of dense-core vesicles. Sci Adv, 3(7):e1603208, 2017. ISSN 2375-2548 (Electronic) 2375-2548 (Linking). doi: 10.1126/sciadv. 1603208 .

19. A. Kreutzberger, V. Kiessling, C. Stroupe, B. Liang, J. Preobraschenski, M. Ganzella, M.A.B. Kreutzberger, R. Nakamoto, R. Jahn, J. D. Castle, and L.K. Tamm. In vitro fusion of single synaptic and dense core vesicles reproduces key physiological properties. Nat Commun, In Press.

20. R. Zdanowicz, A. Kreutzberger, B. Liang, V. Kiessling, L. K. Tamm, and D. S. Cafiso. Complexin binding to membranes and acceptor t-snares explains its clamping effect on fusion. Biophys J, 113(6):1235-1250, 2017. ISSN 1542-0086 (Electronic) 0006-3495 (Linking). doi: 10.1016/j.bpj.2017.04.002.

21. M. K. Domanska, V. Kiessling, A. Stein, D. Fasshauer, and L. K. Tamm. Single vesicle millisecond fusion kinetics reveals number of snare complexes optimal for fast snare-mediated membrane fusion. J Biol Chem, 284(46):32158-66, 2009. ISSN 1083-351X (Electronic) 0021-9258 (Linking). doi: 10.1074/jbc.M109.047381.

22. E. Kalb, S. Frey, and L. K. Tamm. Formation of supported planar bilayers by fusion of vesicles to supported phospholipid monolayers. Biochim Biophys Acta, 1103(2):307-16, 1992. ISSN 0006-3002 (Print) 0006-3002 (Linking).

23. M. L. Wagner and L. K. Tamm. Reconstituted syntaxin1a/snap25 interacts with negatively charged lipids as measured by lateral diffusion in planar supported bilayers. Biophys J, 81(1):266-75, 2001. ISSN 0006-3495 (Print) 0006-3495 (Linking). doi: 10.1016/ S0006-3495(01)75697-4.

24. M. K. Domanska, V. Kiessling, and L. K. Tamm. Docking and fast fusion of synaptobrevin vesicles depends on the lipid compositions of the vesicle and the acceptor snare complexcontaining target membrane. Biophys J, 99(9):2936-46, 2010. ISSN 1542-0086 (Electronic) 0006-3495 (Linking). doi: 10.1016/j.bpj.2010.09.011.

25. A. J. B. Kreutzberger, V. Kiessling, B. Liang, S. T. Yang, J. D. Castle, and L. K. Tamm. Asymmetric phosphatidylethanolamine distribution controls fusion pore lifetime and probability. Biophys J, 113(9):1912-1915, 2017. ISSN 1542-0086 (Electronic) 0006-3495 (Linking). doi: 10.1016/j.bpj.2017.09.014.

26. A. Anantharam, B. Onoa, R. H. Edwards, R. W. Holz, and D. Axelrod. Localized topological changes of the plasma membrane upon exocytosis visualized by polarized tirfm. $\mathrm{J} \mathrm{Cell} \mathrm{Biol,}$ 188(3):415-28, 2010. ISSN 1540-8140 (Electronic) 0021-9525 (Linking). doi: 10.1083/jcb. 200908010.

27. David Perrais, Ingo C. Kleppe, Justin W. Taraska, and Wolfhard Almers. Recapture after exocytosis causes differential retention of protein in granules of bovine chromaffin cells. The Journal of Physiology Online, 560(2):413-428, 2004.

28. A. N. Weiss, A. Anantharam, M. A. Bittner, D. Axelrod, and R. W. Holz. Lumenal protein within secretory granules affects fusion pore expansion. Biophys J, 107(1):26-33, 2014. ISSN 1542-0086 (Electronic) 0006-3495 (Linking). doi: 10.1016/j.bpj.2014.04.064.

29. A. Bhalla, W. C. Tucker, and E. R. Chapman. Synaptotagmin isoforms couple distinct ranges 
of ca2+, ba2+, and sr2+ concentration to snare-mediated membrane fusion. Mol Biol Cell, 16(10):4755-64, 2005. ISSN 1059-1524 (Print) 1059-1524 (Linking). doi: 10.1091/mbc. E05-04-0277.

30. S. Sugita, O. H. Shin, W. Han, Y. Lao, and T. C. Sudhof. Synaptotagmins form a hierarchy of exocytotic ca(2+) sensors with distinct ca(2+) affinities. EMBO J, 21(3):270-80, 2002. ISSN 0261-4189 (Print) 0261-4189 (Linking). doi: 10.1093/emboj/21.3.270.

31. S. Sugita and T. C. Sudhof. Specificity of ca2+-dependent protein interactions mediated by the c2a domains of synaptotagmins. Biochemistry, 39(11):2940-9, 2000. ISSN 0006-2960 (Print) 0006-2960 (Linking).

32. M. Bendahmane, K. P. Bohannon, M. M. Bradberry, T. C. Rao, M. W. Schmidtke, P. S. Abbineni, N. L. Chon, S. Tran, H. Lin, E. R. Chapman, J. D. Knight, and A. Anantharam. The synaptotagmin $\mathrm{c} 2 \mathrm{~b}$ domain calcium-binding loops modulate the rate of fusion pore expansion. Molecular Biology of the Cell, 29(7):834-845, 2018. ISSN 1059-1524. doi: 10.1091/mbc.E17-11-0623.

33. W. W. Douglas. Stimulus-secretion coupling: the concept and clues from chromaffin and other cells. Br J Pharmacol, 34(3):451-74, 1968. ISSN 0007-1188 (Print) 0007-1188 (Linking).

34. W. W. Douglas, T. Kanno, and S. R. Sampson. Influence of the ionic environment on the membrane potential of adrenal chromaffin cells and on the depolarizing effect of acetylcholine. J.Physiol.(Lond), 191:107-121, 1967.

35. H. Matsuoka, K. Harada, J. Nakamura, M. Fukuda, and M. Inoue. Differential distribution of synaptotagmin-1, $-4,-7$, and -9 in rat adrenal chromaffin cells. Cell Tissue Res, 344(1):41-50, 2011. ISSN 1432-0878 (Electronic) 0302-766X (Linking). doi: 10.1007/s00441-011-1131-8.

36. Z. Zhang, Y. Wu, Z. Wang, F. M. Dunning, J. Rehfuss, D. Ramanan, E. R. Chapman, and M. B. Jackson. Release mode of large and small dense-core vesicles specified by different synaptotagmin isoforms in pc12 cells. Mol Biol Cell, 22(13):2324-36, 2011. ISSN 19394586 (Electronic) 1059-1524 (Linking). doi: 10.1091/mbc.E11-02-0159.

37. S. L. Jackman, J. Turecek, J. E. Belinsky, and W. G. Regehr. The calcium sensor synaptotagmin 7 is required for synaptic facilitation. Nature, 529(7584):88-91, 2016. ISSN 14764687 (Electronic) 0028-0836 (Linking). doi: 10.1038/nature16507.

38. J. P. Weber, T. L. Toft-Bertelsen, R. Mohrmann, I. Delgado-Martinez, and J. B. Sorensen. Synaptotagmin-7 is an asynchronous calcium sensor for synaptic transmission in neurons expressing snap-23. PLoS One, 9(11):e114033, 2014. ISSN 1932-6203 (Electronic) 19326203 (Linking). doi: 10.1371/journal.pone.0114033.

39. W. Han, J. S. Rhee, A. Maximov, Y. Lao, T. Mashimo, C. Rosenmund, and T. C. Sudhof. Nglycosylation is essential for vesicular targeting of synaptotagmin 1. Neuron, 41(1):85-99, 2004. ISSN 0896-6273 (Print) 0896-6273 (Linking).

40. S. E. Kwon and E. R. Chapman. Glycosylation is dispensable for sorting of synaptotagmin 1 but is critical for targeting of sv2 and synaptophysin to recycling synaptic vesicles. $J$ Biol Chem, 287(42):35658-68, 2012. ISSN 1083-351X (Electronic) 0021-9258 (Linking). doi: $10.1074 / \mathrm{jbc} . \mathrm{M} 112.398883$.

41. A. R. Flannery, C. Czibener, and N. W. Andrews. Palmitoylation-dependent association with cd63 targets the ca2+ sensor synaptotagmin vii to lysosomes. J Cell Biol, 191(3):599-613, 2010. ISSN 1540-8140 (Electronic) 0021-9525 (Linking). doi: 10.1083/jcb.201003021.

42. J. K. Jaiswal, S. Chakrabarti, N. W. Andrews, and S. M. Simon. Synaptotagmin vii restricts fusion pore expansion during lysosomal exocytosis. PLOS Biol, 2(8):E233, 2004. ISSN 1545-7885 (Electronic) 1544-9173 (Linking). doi: 10.1371/journal.pbio.0020233.

43. Bryan W. Doreian, Tiberiu G. Fulop, and Corey B. Smith. Myosin ii activation and actin reorganization regulate the mode of quantal exocytosis in mouse adrenal chromaffin cells. Journal of Neuroscience, 28(17):4470-4478, 2008.

44. Tiberiu Fulop, Bryan Doreian, and Corey Smith. Dynamin i plays dual roles in the activitydependent shift in exocytic mode in mouse adrenal chromaffin cells. Archives of Biochemistry and Biophysics, 477(1):146-154, 2008.

45. A. Gucek, N. R. Gandasi, M. Omar-Hmeadi, M. Bakke, S. O. Doskeland, A. Tengholm, and $\mathrm{S}$. Barg. Fusion pore regulation by camp/epac2 controls cargo release during insulin exocytosis. Elife, 8, 2019. ISSN 2050-084X (Electronic) 2050-084X (Linking). doi: 10.7554/ eLife.41711.

46. Q. Wu, Q. Zhang, B. Liu, Y. Li, X. Wu, S. Kuo, L. Zheng, C. Wang, F. Zhu, and Z. Zhou. Dynamin 1 restrains vesicular release to a subquantal mode in mammalian adrenal chromaffin cells. J Neurosci, 39(2):199-211, 2019. ISSN 1529-2401 (Electronic) 0270-6474 (Linking). doi: 10.1523/JNEUROSCI.1255-18.2018.

47. W. D. Zhao, E. Hamid, W. Shin, P. J. Wen, E. S. Krystofiak, S. A. Villarreal, H. C. Chiang, B. Kachar, and L. G. Wu. Hemi-fused structure mediates and controls fusion and fission in live cells. Nature, 534(7608):548-52, 2016. ISSN 1476-4687 (Electronic) 0028-0836 (Linking). doi: 10.1038/nature18598.

48. P. S. Abbineni, D. Axelrod, and R. W. Holz. Visualization of expanding fusion pores in secretory cells. J Gen Physiol, 2018. ISSN 1540-7748 (Electronic) 0022-1295 (Linking). doi: 10.1085 /jgp.201812186.

49. E. Neher and G. J. Augustine. Calcium gradients and buffers in bovine chromaffin cells. $J$ Physiol, 450:273-301, 1992. ISSN 0022-3751 (Print) 0022-3751 (Linking).

50. M. A. Bittner and R. W. Holz. Kinetic analysis of secretion from permeabilized adrenal chromaffin cells reveals distinct components. Journal of Biological Chemistry, 267:1621916225, 1992.

51. S. Chakrabarti, K. S. Kobayashi, R. A. Flavell, C. B. Marks, K. Miyake, D. R. Liston, K. T. Fowler, F. S. Gorelick, and N. W. Andrews. Impaired membrane resealing and autoimmune myositis in synaptotagmin vii-deficient mice. J Cell Biol, 162(4):543-9, 2003. ISSN 00219525 (Print) 0021-9525 (Linking). doi: 10.1083/jcb.200305131. 


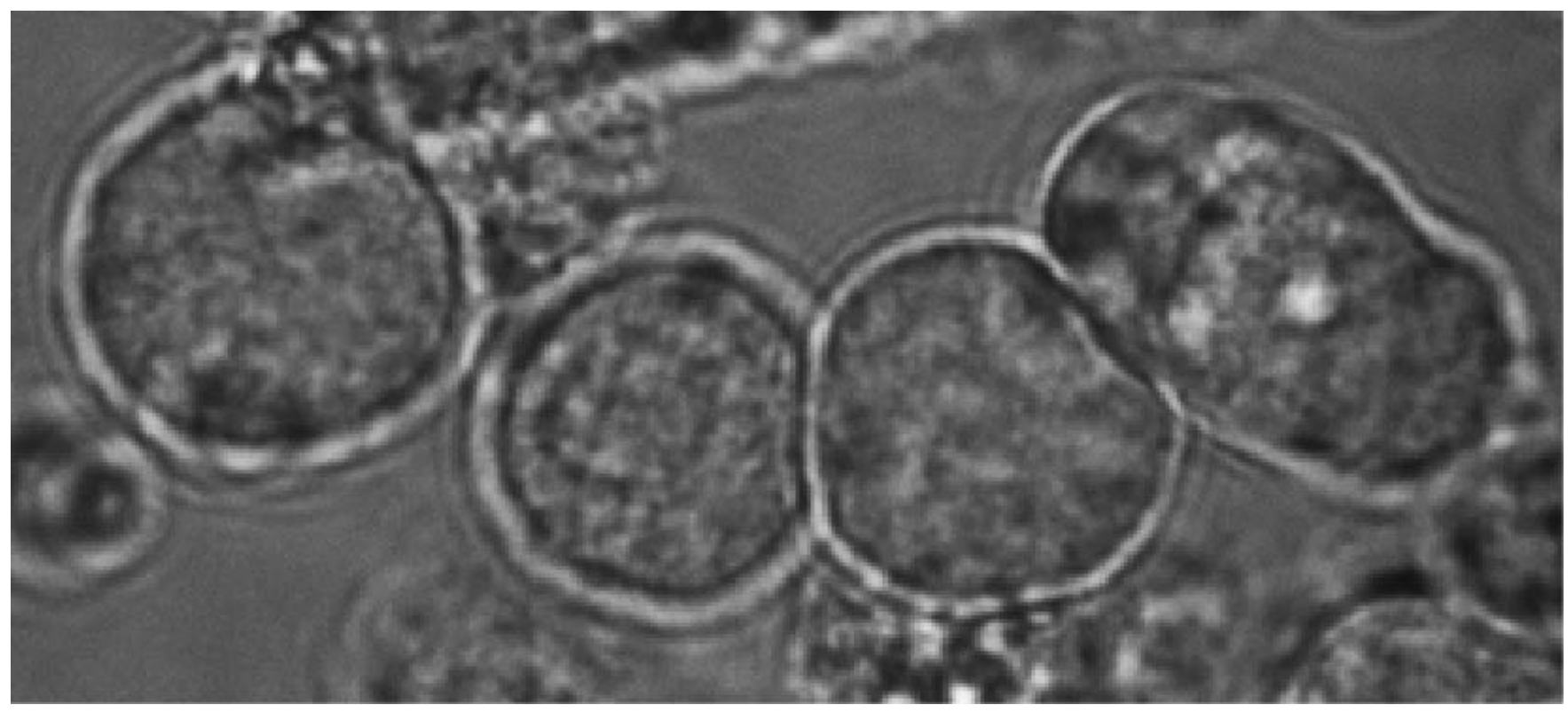

Fig. S1. Mouse chromaffin cells 24 hours after plating on Matrigel-coated glass bottom dishes. Mouse chromaffin cells 24 hours after plating on Matrigel-coated glass bottom dishes. 


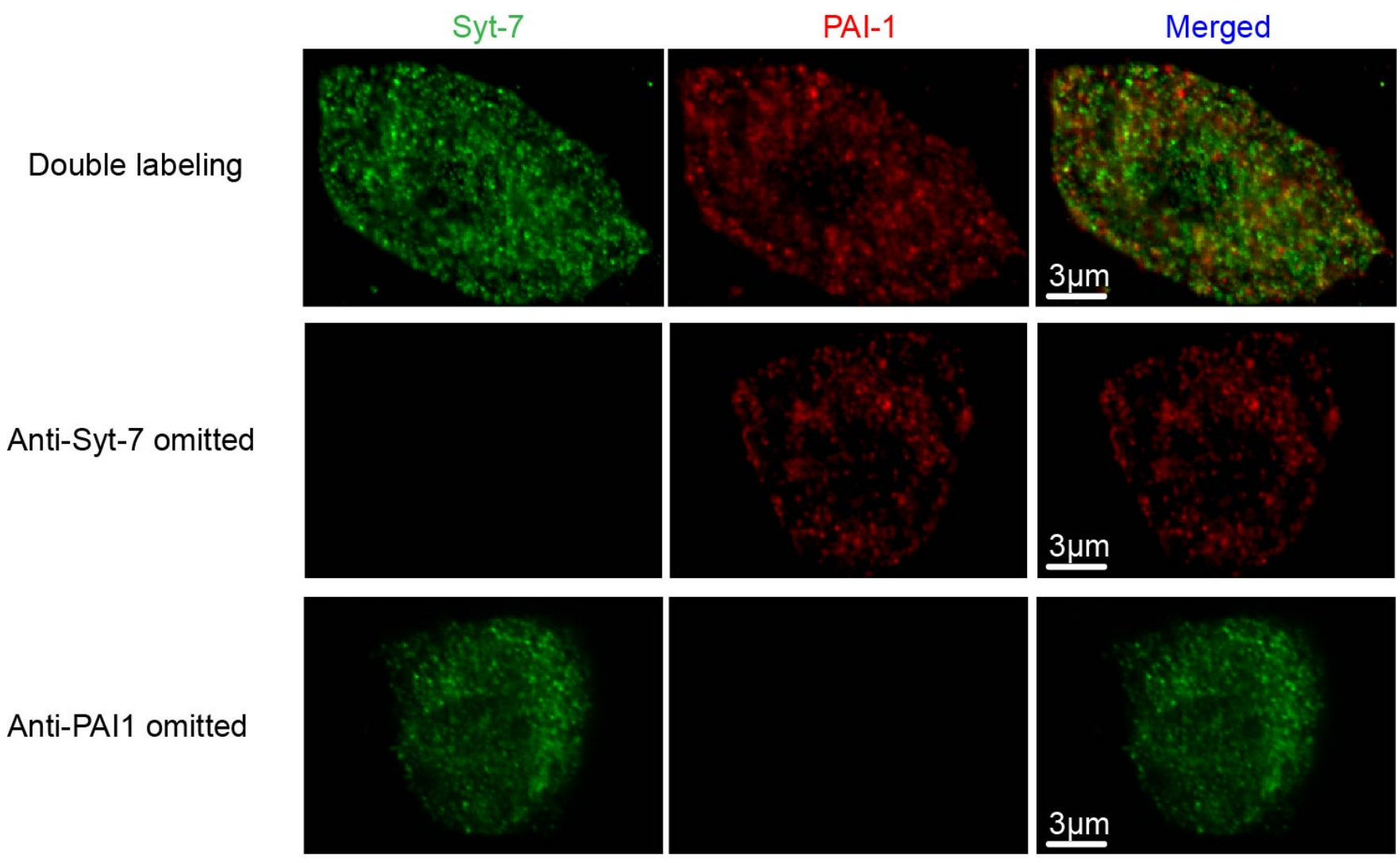

Fig. S2. Validation of immunocytochemical-staining method using two primary antibodies raised in rabbit. Images show double-labeling for Syt-7 and PAI-1 (top row, image from figure 1). No detectable labeling was seen when of one primary antibodies was omitted (Syt-7, middle row and PAI-1 bottom row). 
A

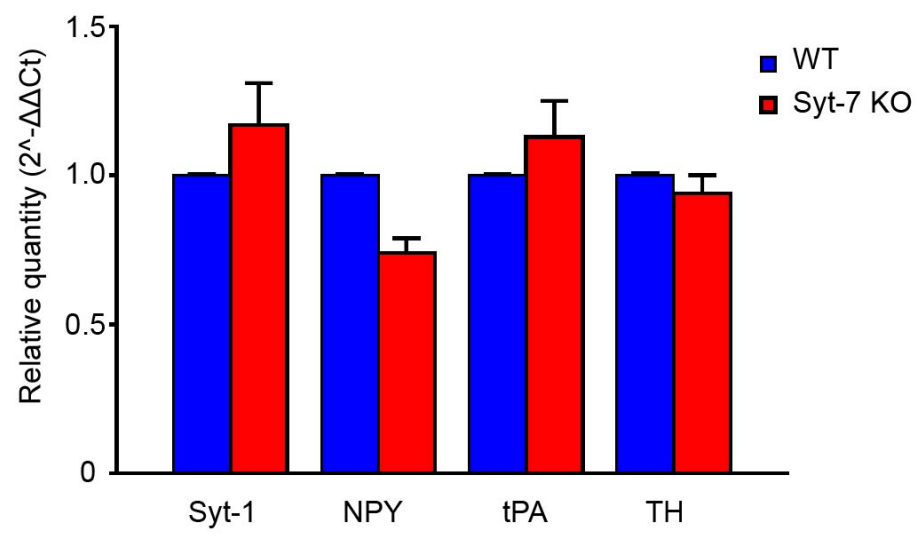

B

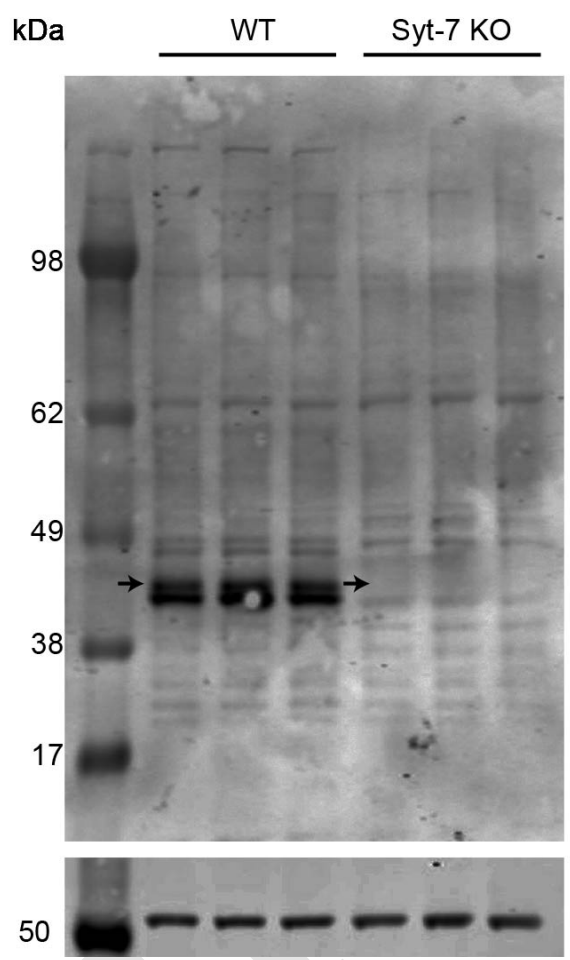

Syt-7

Alpha tubulin

Fig. S3. A. Expression of Syt-1, NPY, tPA, and TH transcripts in WT and Syt-7 KO chromaffin cells. WT and KO adrenal medullas were homogenized, mRNA was extracted and RT-qPCR was performed on the samples for Syt-1 $(n=5), N P Y(n=3)$, tPA $(n=3)$, TH $(n=3)$, and Syt-7 $(n=2)$. Syt-7 transcript was not detected using the primers shown in Table 1. Expression of Syt-1 mRNA was not significantly different in WT and KO cells (Student's t-test, $p>0.05$ ). B. Western Blot analysis was performed on WT and Syt-7 KO adrenal glands. Boxed region (white) indicates the region where the approximately $45 \mathrm{kDa}$ Syt-7 alpha variant should be observed (8, 51). It is present in the WT lanes but not in the Syt-7 KO lanes. 

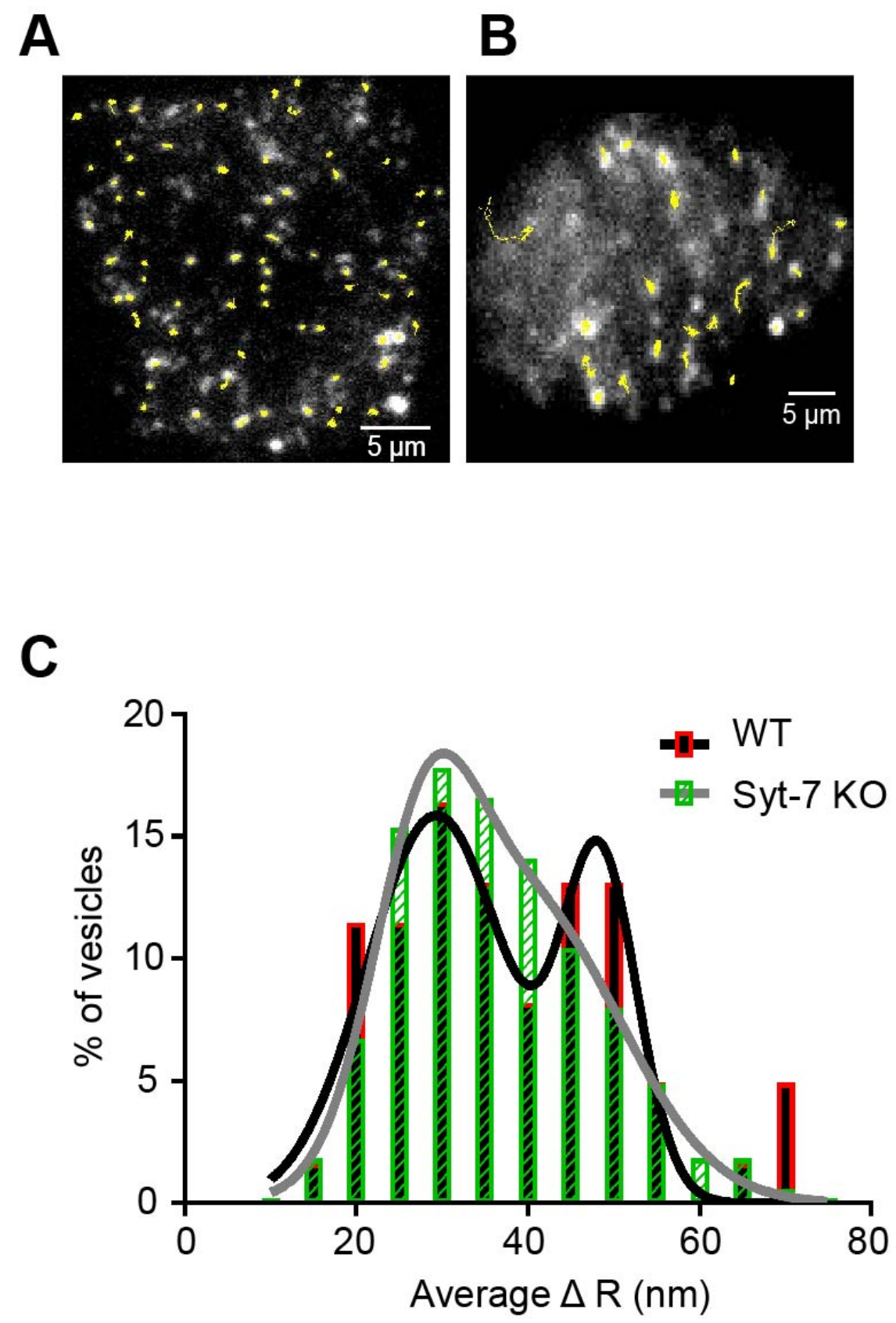

Fig. S4. An analysis of vesicle motion in WT and Syt-7 KO cells. A-B. Representative tracks of WT (A) and Syt-7 KO (B) vesicles. C. Average mean frame-to-frame displacement of slower and faster WT vesicle populations, $29.32+/-1.41 \mathrm{~nm} /$ frame and $48.39+/-$ $1.13 \mathrm{~nm}$ respectively, and slower and faster Syt-7 KO vesicles, $27.82+/-0.59 \mathrm{~nm} /$ frame, and $39.97+/-3.76 \mathrm{~nm} /$ frame respectfully. 
bioRxiv preprint doi: https://doi.org/10.1101/704205; this version posted July 16, 2019. The copyright holder for this preprint (which was not certified by peer review) is the author/funder. All rights reserved. No reuse allowed without permission.

Movie S1. Example of a WT mouse chromaffin cell expressing NPY GFP and stimulated with $100 \mathrm{mM}$ KCl. Secretion was imaged with a TIRF microscope (see Methods). Corresponds to cell shown in Figure 3.

Movie S2. Example of a WT mouse chromaffin cell expressing NPY GFP and stimulated with $100 \boldsymbol{\mu M}$ ACh. Secretion was imaged with a TIRF microscope (see Methods). Corresponds to cell shown in Figure 5. 